\title{
Fluorinated MOF-808 with various modulators to fabricate high-performance hybrid membranes with enhanced hydrophobicity for organic-organic pervaporation
}

\author{
Katarzyna Knozowska ${ }^{1}$, Raymond Thür ${ }^{2}$, Joanna Kujawa ${ }^{1}$, Iryna Kolesnyk ${ }^{3}$, \\ Ivo F. J. Vankelecom ${ }^{2}$, Wojciech Kujawski ${ }^{1, *}$
}

\begin{abstract}
${ }^{1}$ Nicolaus Copernicus University in Toruń, Faculty of Chemistry, 7 Gagarina Street, 87-100 Toruń, Poland

${ }^{2}$ Membrane Technology Group (cMACS), Centre for Membrane Separations, Adsorption, Catalysis and Spectroscopy for Sustainable Solutions (cMACS), KU Leuven, Celestijnenlaan 200F, Box 2454, 3001 Heverlee, Vlaams-Brabant, Belgium

${ }^{3}$ Department of Chemistry, National University of Kyiv-Mohyla Academy, Skovorody str. 2, Kyiv, Ukraine

*Corresponding author (W. Kujawski), phone: +48 5661145 17, fax: +48 5661145 26; email: wkujawski@umk.pl
\end{abstract}

\begin{abstract}
Highly efficient PDMS based membranes with a new type of fluorinated MOF-808 were successfully prepared and used for the first time in pervaporation (PV). Two types of ligands i.e. trifluoroacetic acid (TFA) and pentafluoropropionic acid (PFPA) were used during the MOF synthesis. These ligands with slightly different size and chemical character influenced the material properties of the membranes, i.e. roughness, contact angle, surface free energy, and thermal features. Incorporation of MOFs enhanced the membrane hydrophobicity and the performance in organic-organic PV for the separation of industrially important mixtures like, ethyl acetate-EtAc and ethyl tert-butyl ether-ETBE. The filled membranes possessed much better transport and separation features than the pristine PDMS. Substantial improvement of modified membrane performance with $5 \mathrm{wt} \%$ MOF (normalized Pervaporation Separation Index $\left.-P S I_{N}=1540 \mu \mathrm{m} \mathrm{kg} \mathrm{m}^{-2} \mathrm{~h}^{-1}\right)$ was observed in relation to pristine PDMS $\left(P S I_{N}=780 \mu \mathrm{m} \mathrm{kg}\right.$ $\left.\mathrm{m}^{-2} \mathrm{~h}^{-1}\right)$ and commercial Pervap4060 $\left(P S I_{N}=150 \mu \mathrm{m} \mathrm{kg} \mathrm{m} \mathrm{m}^{-2} \mathrm{~h}^{-1}\right)$, during the separation of $\mathrm{ETBE} / \mathrm{EtOH}$. An important added value was the study of the impact of water traces (in the range 0.1-0.3 $\mathrm{wt} \%$ ) in the feed on the membrane performance. The level of water in the permeate was dependent on the membrane material composition, i.e. the MOF loading, since the presence of hydrophobic MOF restricted the transport of water to the permeate side.
\end{abstract}


Keyword: organic-organic pervaporation, filled membrane, fluorinated MOF-808, Hansen's Solubility Parameters
Abbreviations
A
active area of membrane $\left[\mathrm{m}^{2}\right]$
$A F M$
atomic force microscopy
$B D C$
1,4-benzenedicarboxylate
$B E T$
Brunauer-Emmett-Teller isotherm
BTC
1,3,5-benzenetricarboxylate
$C A$
contact angle $\left[{ }^{\circ}\right]$
$C A U$
Christian-Albrechts-University
CLA
cellulose acetate
EF
enrichment factor [-]
EtAc
ethyl acetate
ETBE
ethyl tert-butyl ether
$\mathrm{EtOH}$
ethanol
FC12
$1 \mathrm{H}, 1 \mathrm{H}, 2 \mathrm{H}, 2 \mathrm{H}$-perfluorotetradecyltriethoxysilane
$F_{w}$
water content in feed [wt\%]
HKAUST-1
Hong Kong University of Science and Technology [ $\left.\mathrm{Cu}_{3}(\mathrm{BTC})_{2}\right]$
HSP
Hansen's Solubility Parameters $\left[\mathrm{MPa}^{1 / 2}\right]$
IPA
isopropanol
IRMOF
iso-reticular metal-organic frameworks
$J_{i}$
partial permeate flux of component $i\left[\mathrm{~g} \mathrm{~m}^{-2} \mathrm{~h}^{-1}\right]$
$J_{t}$
total permeate flux $\left[\mathrm{g} \mathrm{m}^{-2} \mathrm{~h}^{-1}\right]$
$l$
thickness of membrane $[\mu \mathrm{m}]$
$L O D$
limit of detection [\%]
$L O Q$
limit of quantification [\%]
$m$
mass of permeate collected over given period of time $[\mathrm{g}]$
MIL
Material Institute Lavoisier
$M M M$
Mixed Matrix Membrane
MOF
metal-organic framework
PDMS
poly(dimethylsiloxane)
PFPA
pentafluoropropionic acid
PLA
poly(lactide) 


\begin{tabular}{|c|c|}
\hline PLLA & poly(L-lactic acid) \\
\hline$P S I_{N}$ & thickness normalized Pervaporation Separation Index $\left[\mu \mathrm{m} \mathrm{g} \mathrm{m}^{-2} \mathrm{~h}^{-1}\right]$ \\
\hline$P V P$ & poly(vinyl pyrrolidone) \\
\hline$P_{w}$ & water content in permeate $[\mathrm{wt} \%]$ \\
\hline$R_{a}$ & distance in the Hansen's space between solvent and solute [-] \\
\hline$R_{A}$ & roughness parameter $[\mathrm{nm}]$ \\
\hline$R E D$ & relative energy difference [-] \\
\hline$R_{o}$ & radius of the solubility sphere (interaction radius) [-] \\
\hline$S B U$ & secondary build unit \\
\hline$S E M$ & scanning electron microscopy \\
\hline$S F E$ & surface free energy $\left[\mathrm{N} \mathrm{m}^{-1}\right]$ \\
\hline SW & degree of swelling $[\%]$ \\
\hline$t$ & time of permeate collection $[\mathrm{h}]$ \\
\hline$T C D$ & thermal conductivity detector \\
\hline$T E M$ & transmission electron microscopy \\
\hline$T F A$ & trifluoroacetic acid \\
\hline$T_{g}$ & glass transition temperature $[\mathrm{K}]$ \\
\hline$T G A$ & thermal gravimetric analysis \\
\hline$U P$ & uptake degree $[\%]$ \\
\hline$W_{d}$ & mass of dry membrane $[\mathrm{g}]$ \\
\hline$W_{s}$ & mass of swollen membrane $[\mathrm{g}]$ \\
\hline$x_{i}$ & mass fraction of component $i$ in feed [-] \\
\hline$X R D$ & $\mathrm{X}$-ray diffraction \\
\hline$y_{i}$ & mass fraction of component $i$ in permeate [-] \\
\hline$Z I F$ & zeolitic imidazolate frameworks \\
\hline$\beta$ & separation factor [-] \\
\hline$\gamma_{g}$ & surface free energy of glicerol $\left[\mathrm{N} \mathrm{m}^{-1}\right]$ \\
\hline$\gamma_{L}$ & surface free energy of measuring liquid $\left[\mathrm{N} \mathrm{m}^{-1}\right]$ \\
\hline$\gamma_{L V}$ & surface interfacial free energy of liquid-vapour $\left[\mathrm{N} \mathrm{m}^{-1}\right]$ \\
\hline$\gamma_{s}$ & surface interfacial free energy of solid $\left[\mathrm{N} \mathrm{m}^{-1}\right]$ \\
\hline$\gamma_{S L}$ & surface interfacial free energy of solid-liquid $\left[\mathrm{N} \mathrm{m}^{-1}\right]$ \\
\hline$\gamma_{S V}$ & surface interfacial free energy of solid-vapour $\left[\mathrm{N} \mathrm{m}^{-1}\right]$ \\
\hline$\gamma_{w}$ & surface free energy of water $\left[\mathrm{N} \mathrm{m}^{-1}\right]$ \\
\hline$\Delta$ & distance parameter $\left[\mathrm{MPa}^{1 / 2}\right]$ \\
\hline
\end{tabular}




$\begin{array}{ll}\delta_{d} & \text { dispersion interactions }\left[\mathrm{MPa}^{1 / 2}\right] \\ \delta_{h} & \text { hydrogen bonding interactions }\left[\mathrm{MPa}^{1 / 2}\right] \\ \delta_{p} & \text { polar interactions }\left[\mathrm{MPa}^{1 / 2}\right] \\ \theta & \text { contact angle }\left[^{\circ}\right] \\ \theta_{\mathrm{g}} & \text { contact angle of glycerol }\left[{ }^{\circ}\right] \\ \theta_{\mathrm{w}} & \text { contact angle of water }\left[{ }^{\circ}\right]\end{array}$

\section{Introduction}

The problem of the solvent utilization reduction in various industries remains challenging; therefore, effective strategies for solvent recycling are highly desirable.

Pervaporation is considered a green alternative for traditional technologies applied for the separation and/or recovery of mixtures of organic liquid solvents [1-4]. Pervaporation is a membrane-based technique applied for the separation of binary or multi-component liquid mixtures, including azeotrope, isomer, enantiomer, and close-boiling systems. Generally, dense polymeric membranes are utilized $[5,6]$. The way to overcome the problem of separation efficiency selectivity is the preparation of filled membranes (Mixed Matrix Membranes MMMs) [7, 8]. The incorporation of well selected fillers into a membrane matrix increases separation performance [8], as it can change the membrane hydrophilicity/hydrophobicity, antifouling properties, and decrease the membrane swelling [9].

Nowadays, metal-organic frameworks (MOFs) are the most commonly used fillers, [10]. MOFs are crystalline nanoporous materials, consisting of metal ions or metal clusters (so-called SBU - secondary build units) coordinated with organic ligands. The bonds between a metal cluster and the organic ligand are strong, which makes the MOFs' structure well defined and stable [11]. Because of the presence of organic ligands in the structure, MOFs mostly show a good compatibility with the polymer matrix compared to inorganic fillers [11].

During the last decade, mostly MOF-5, HKAUST-1, IRMOF, ZIF, MIL, and CAU have been used for the preparation of filled MMMs. However, results showed that these compounds often possess low hydrothermal and chemical stability [10]. The stability of MOFs in the presence of water plays a key role in the pervaporation. It was observed that the character and properties of the metal ion influence the bond strength between metal ion and ligands. MOFs with metals from the IV group ( $\mathrm{Ti}, \mathrm{Zr}, \mathrm{Hf}$ ) showed high chemical stability [12]. Due to that fact, Zr-based MOFs have been selected as promising fillers. Additionally, based on Pearson's hard/soft acid/base theory, $\mathrm{Zr}$ in its +4 oxidation state creates strong bonds with carboxylate 
ligands, which leads to the formation of a thermodynamically stable structure $[10,12]$. UiO-66 (UiO - University of Oslo), an example of Zr-MOF [13] consisting of Zr-oxo clusters $\left(\mathrm{Zr}_{6} \mathrm{O}_{4}(\mathrm{OH})_{4}\right)$ connected by 12 1,4-benzenedicarboxylate $\left(\mathrm{BDC}^{2-}\right)$ ligands, has been extensively studied in pervaporation and gas separation [14-18].

Modification of MOFs is performed to create a specific functional group or active center useful in potential applications, like e.g. catalysis $[19,20]$. However, the cluster coordination sphere of UiO-66 is theoretically occupied by $12 \mathrm{BDC}^{2-}$ ligands, which impedes the structure modification process. MOF-808 is similar to UiO-66, consisting of the same Zr-cluster $\left(\mathrm{Zr}_{6} \mathrm{O}_{4}(\mathrm{OH})_{4}\right)$ connected with only six 1,3,5-benzenetricarboxylate $\left(\mathrm{BTC}^{3-}\right)$ linkers [21]. This means that the other six planar coordination sites are available to introduce the functionalized ligands. Moreover, MOF-808 is characterized by a high specific surface area, large pore volume, excellent chemical, and mechanical stability [22].

As mentioned before, the reduction of solvent application and its recycling is essential in the modern industry. Particularly, ethyl acetate and ethyl tert-butyl ether are industrially important organic solvents having great meaning for the petrochemical industry. Ethyl tertbutyl ether (ETBE) is applied as an oxygenate additive for lessening air pollution without causing harmful impacts on human health [23-25]. Moreover, ETBE can be formed from renewable sources, e.g. biomass, cellulose, bio-ethanol [26].

Ethyl acetate (EtAc), commonly used in a broad range of applications, e.g. pharmaceuticals, petroleum, and electric industry, textile, cosmetics, is expected to witness steady growth in the future, owing to its low cost and toxicity levels [27, 28]. Growing product consumption and demand as a flavor enhancer in the beverage and food industry is also driving the market of EtAc [29].

As EtAc and ETBE are industrially important organic solvents, it is beneficial to recycle both solvents from an economical and environmental point of view. Researchers developed various separation materials dedicated to solvents separation. Hasanoğlu et al. [30] evaluated poly(dimethylsiloxane) (PDMS) based membranes in the separation of ethyl acetate/ethanol mixtures. PDMS membranes showed the best efficiency $(\beta=3)$ in the separation of mixtures containing $40 \mathrm{wt} \%$ of EtAc [30]. Knozowska et al. [31] separated ethyl acetate/ethanol and ethyl acetate/isopropanol, applying MMMs based on PDMS and Pebax 2533. The authors modified the membranes by incorporating hydrophobized aluminium oxides grafted with various alkylsilanes and perfluoroalkylsilane. The incorporation of hydrophobized filler increased the membrane's separation efficiency. PDMS/( $\left.\mathrm{Al}_{2} \mathrm{O}_{3}+\mathrm{FC} 12\right)$ membrane 
demonstrated the best performance with a separation factor $\left(\beta_{E t A c / E t O H}=4.3\right)$ that was $160 \%$ higher than for the pristine PDMS membrane [31].

In the case of separation of ethyl tert-butyl ether (ETBE)/ethanol mixtures, various polymers, like poly(lactide), poly(vinyl pyrrolidone), poly(amide-imide), poly(urethaneamide-imide) have been applied [32-35]. In the purification of ETBE, the performance of poly(lactide)/poly(vinyl pyrrolidone) (PLA/PVP) membranes strongly depended on the content of PLA in the membrane matrix [35]. The best separation ability was found for the membrane with $3 \mathrm{wt} \%$ PVP, demonstrating a high flux of $2.7 \mathrm{~kg} / \mathrm{m}^{2} \mathrm{~h}$ and high ethanol content in the permeate $(80 \mathrm{wt} \%)$ [35]. Using cellulose acetate/poly(lactide) (CLA/PLA) membranes, an increase in the PLA content in the membrane matrix resulted in an increase of the thickness normalized flux and ethanol permeability [34]. The thickness normalized flux and ethanol permeability for the CA/PLA-40.5 membrane were 12 and 11 times higher than those for the pristine CA one [34]. Jonquières et al. [33] synthesized new types of the poly(urethane-amide-imide) with various soft segments, showing that polymers with longer soft segments possessed a better separation efficiency [33].

In the separation of ETBE/ethanol, mainly hydrophilic membranes are used. For that reason, we decided to choose hydrophobic PDMS to extend the existing knowledge in the separation of this mixture and gain information whether the hydrophobic polymer is also suitable for this application.

A fluorinated MOF-808 was designed and developed by using perfluoro carboxylic acids (i.e. trifluoroacetic acid (TFA) and pentafluoropropionic acid (PFPA)) modulators to increase the hydrophobic character of the compound. Subsequently, modified MOF-808 (MOF-808-TFA and MOF-808-PFPA) was incorporated into PDMS matrix and tested in the pervaporative separation of organic solvent mixtures (ethyl acetate/ethanol, ethyl acetate/isopropanol, and ethyl tert-butyl ether/ethanol). Moreover, for the first time, modified MOF-808 was applied as a filler in pervaporation membranes.

\section{Theoretical part}

\subsection{Wetting analysis}

The wettability analysis consisted of the contact angle $(C A)$ and surface free energy (SFE) determination.

The Young's equation (Eq. (1)) combines the value of the contact angle $(\theta)$ and surface free energies $(\gamma)$ between solid-vapour $\left(\gamma_{S V}\right)$, solid-liquid $\left(\gamma_{S L}\right)$, and liquid-vapour $\left(\gamma_{L V}\right)$ [36]. 
$\gamma_{S V}=\gamma_{S L}+\gamma_{L V} \cos \theta$

where $\gamma_{S V}$ is a surface interfacial free energy of solid-vapour, $\gamma_{S L}$ is a surface interfacial free energy of solid-liquid, $\gamma_{L V}$ is a surface interfacial free energy of liquid-vapour, and $\theta$ is a contact angle.

As $\gamma_{S L}$ and $\gamma_{S V}$ cannot be determined experimentally, therefore Dupré's equation (Eq.(2)) is used to find the values of these coefficients [36].

$W_{S L}^{a}=\gamma_{S}+\gamma_{L}+\gamma_{S L}$

A combination of Eq. (1) and Eq. (2) leads to the Young-Dupré's equation (Eq. (3)), which is used for the determination of the surface free energy of polymers.

$W_{S L}^{a}=\gamma_{L} \cdot(1+\cos \theta)$

where $\gamma_{L}$ is a surface free energy of measured liquid while $W_{S L}$ is reversible thermodynamic adhesive work and is equal to surface free energy [36].

Surface free energy was determined based on measuring the contact angle measurements of two liquids with different polarities (e.g. water and glycerol) and the known values of their surface tension. One of the methods applied for the calculation of surface free energy (SFE) is the approach proposed by Owens-Wendt. This method assumes that SFE is a sum of dispersion component $\left(\gamma_{S D}\right)$ and polar component $\left(\gamma_{S P}\right)$ according to the Eq. (4) [36]:

$\gamma_{S L}=\gamma_{S}+\gamma_{L}-2 \sqrt{\left(\gamma_{S}^{D} \gamma_{L}^{D}\right)}-2 \sqrt{\left(\gamma_{S}^{P} \gamma_{L}^{P}\right)}$

where $\gamma_{S L}$ is a surface interfacial free energy of solid-liquid, $\gamma_{S}$ is a surface interfacial free energy of solid, $\gamma_{L}$ is the surface free energy of measuring liquid, and superscripts $d$ and $p$ correspond to dispersion and polar interaction, respectively.

The dispersive component of surface free energy is calculated using Eq. (5) [36]:

$\left(\gamma_{S}^{D}\right)^{0,5}=\frac{\gamma_{g}\left(\cos \theta_{g}+1\right)-\gamma_{w}\left(\cos \theta_{w}+1\right) \sqrt{\frac{\gamma_{g}^{P}}{\gamma_{w}^{P}}}}{2\left[\sqrt{\gamma_{g}^{D}}-\sqrt{\gamma_{g}^{P} \frac{\gamma_{w}^{D}}{\gamma_{w}^{P}}}\right]}$

While the polar component of surface free energy is determined using Eq. (6) [36]:

$\left(\gamma_{S}^{P}\right)^{0,5}=\frac{\gamma_{w}\left(\cos \theta_{w}+1\right)-2 \sqrt{\gamma_{S}^{D} \gamma_{w}^{D}}}{2 \sqrt{\gamma_{w}^{P}}}$

where $\gamma_{g}$ is SFE of glycerol, $\gamma_{g}^{D}$ is a dispersive component of SFE of glycerol, $\gamma_{g}^{P}$ is a polar component of SFE of glycerol, $\gamma_{w}$ is SFE of water, $\gamma_{w}^{D}$ is a dispersive component of SFE 
of water, $\gamma_{w}^{P}$ is a polar component of SFE of water, $\cos \theta_{g}$ is a contact angle of glycerol, and $\cos \theta_{w}$ is a contact angle of water.

The values of polar, dispersive, and surface free energy of water and glycerol are gathered in Table 1.

Table 1. Values of the polar, dispersive, and surface free energy of water and glycerol [36].

\begin{tabular}{lccc}
\hline Liquid & $\boldsymbol{\gamma}_{L}\left[\mathbf{1 0}^{-3} \mathbf{N ~ m}^{-1}\right]$ & $\boldsymbol{\gamma}_{L}^{\boldsymbol{D}}\left[\mathbf{1 0}^{-3} \mathbf{N ~ m}^{-1}\right]$ & $\boldsymbol{\gamma}_{L}^{P}\left[\mathbf{1 0}^{-3} \mathbf{N ~ m}^{-1}\right]$ \\
\hline Water & 72.8 & 21.8 & 51.0 \\
Glycerol & 63.4 & 37.0 & 26.4 \\
\hline
\end{tabular}

\subsection{Hansen's Solubility Parameters (HSP)}

To predict and understand the interactions between the separated system and membrane material, the HSP theory was implemented. In pervaporation, the solution-diffusion mechanism is used to describe the transport and separation mechanism [37]. The solution-diffusion model assumes the three stages of separation: solution, diffusion, and desorption. As the membrane polymer matrix swells during contact with solvents, diffusion of the components through the membrane is facilitated. The value of the polymer swelling depends on the interaction and affinity between polymer and solvent. For that reason, the prediction of these interactions is crucial for the selection of the best separation material.

The HSP theory is a valuable tool to tackle this problem. For this purpose, the so-called distance parameter $(\Delta)$ between polymer and solvent should be calculated (Eq. (7)) [5].

$\Delta=\sqrt{\left(\delta_{d, S 1}-\delta_{d, S 2}\right)^{2}+\left(\delta_{p, S 1}-\delta_{p, S 2}\right)^{2}+\left(\delta_{h, S 1}-\delta_{h, S 2}\right)^{2}}$

where $\delta_{d, S 1}, \delta_{d, S 2}$ are a dispersion interaction, $\delta_{p, S 1}, \delta_{p, S 2}$ is polar interaction, and $\delta_{h, S 1}, \delta_{h, S 2}$ is a hydrogen bonding interaction.

According to the definition, the lower the value of $\Delta$ is, the stronger the interactions between the polymer and the solvent. Eq. (7) presents the basic case when non-modified material or pure solvent is used. However, the description becomes more complex for MMMs. As a result of the incorporation of MOFs into the PDMS matrix, the sorption properties of the membrane changed as well as the affinity between the membrane and mixture components altered. In this case, the modified HSP should be calculated (Eq. (8)). There are several methods for determining the HSP, but the approach proposed by Bagley is the most suitable for polymeric membranes [38].

$\delta_{m}=\left[\delta_{d}, \delta_{p}, \delta_{h}\right]=\left[\left(a \cdot \delta_{d 1}+b \cdot \delta_{d 2}\right),\left(a \cdot \delta_{p 1}+b \cdot \delta_{p 2}\right),\left(a \cdot \delta_{h 1}+b \cdot \delta_{h 2}\right)\right] /(a+b)(8)$ 
where: $\delta_{m}$ is a modified HSP parameter for the solvent mixture and heterogenous membrane, $\delta_{d l}, \delta_{p l}, \delta_{h 1}$ are dispersive, polar and hydrogen bonding interactions for the first component, and $\delta_{d 2}, \delta_{p 2}, \delta_{h 2}$ are dispersive, polar and hydrogen bonding interactions for the second component, $a$ is the content of one component of separated mixtures or the content of nanofillers in the filled membrane, and $b$ is the content of the second component of separated mixtures or the content of the polymer matrix in the filled membrane.

Interaction between MOFs and solvent or ligands possesses various natures, i.e. dispersion, polar or hydrogen bonds [39]. These parameters for the PDMS matrix, tested solvents and MOF-808 ligand are given in Table 2. However, in the case of MOFs, the value of affinity between MOF particles and a given solvent depends not only on these parameters but also on the pore size of MOFs and dimensions of the guest molecule [39]. There is available a very limited scientific literature focused on the application of the HSP theory for the prediction of the interaction between a polymeric matrix and MOFs [39, 40]. The best approach for MMMs modified by MOF particles is the assumption that polymer-ligand interactions dominate the MOF-polymer interaction, and that the solubility parameters of the ligand are equal to the solubility parameters of given MOF.

Table 2. Hansen's Solubility Parameters for polymer, solvents, and ligands.

\begin{tabular}{|c|c|c|c|c|}
\hline \multirow{2}{*}{$\begin{array}{l}\text { Solvent, ligand or } \\
\text { polymer }\end{array}$} & \multicolumn{3}{|c|}{ Hansen's Solubility Parameters [MPa $\left.{ }^{0,5}\right]$} & \multirow{2}{*}{ Ref } \\
\hline & $\delta_{d}$ & $\delta_{p}$ & $\delta_{h}$ & \\
\hline PDMS & 15.9 & 0 & 4.1 & {$[41]$} \\
\hline Ethanol & 15.8 & 8.8 & 19.4 & \\
\hline Ethyl acetate & 15.8 & 5.3 & 7.2 & {$[42]$} \\
\hline Isopropanol & 15.8 & 6.1 & 16.4 & {$[42]$} \\
\hline Ethyl tert-butyl ether & 14.9 & 2.1 & 4.5 & \\
\hline BTC & 20.8 & 9.3 & 17.0 & [39] \\
\hline
\end{tabular}

Based on the distance parameters (Eq. 7), it would be possible to predict the stability of the material being in contact with selected solvents or their mixture. The factor describing affinity between solvent and polymer is defined as a relative energy difference (RED) (Eq. 9) [43].

$R E D=R_{a} / R_{o}$

where $R_{a}$ is a distance in the Hansen's space between solvent and solute and $R_{o}$ is a radius of the solubility sphere (interaction radius). In the case of RED $<1$, instability, miscibility or swelling can be noticed. Highly stable material in a certain solvent will be characterized by $R E D>1$ [31]. 


\section{Experimental}

\subsection{Reagents and solvents}

Ethyl acetate, ethanol, and isopropanol were purchased from Chempur (Piekary Śląskie, Poland). Ethyl tert-butyl ether was kindly provided by PKN Orlen S.A. (Płock, Poland).

A commercial, composite poly(dimethylsiloxane) based membrane - Pervap ${ }^{\mathrm{TM}} 4060$ was purchased from DeltaMem AG (Muttenz, Switzerland).

Elastosil LR 6240A (containing platinum catalyst) and Elastosil LR 6240B (containing crosslinker) were provided by Wäcker Chemie Polska Sp. z o.o. (Warszawa, Poland). The viscosity of Elastosil LR 6240A and Elastosil LR 6240B is equal to 30-45 and 25-40 Pa s, respectively.

TFA was acquired from Merck-Schuchardt (Hohenbrunn, Germany), while PFPA was purchased from Sigma-Aldrich (Saint Louis, USA). BTC was purchased from J\&K Chemicals (Lommel, Belgium). Zirconylchloride octahydrate was supplied by Abcr GmbH (Karlsruhe, Germany).

\subsection{Synthesis of MOF-808-TFA and MOF-808-PFPA}

MOF-808-TFA and MOF-808-PFPA were synthesized, as described in [22]. $0.605 \mathrm{mmol}(0.127 \mathrm{~g}) \mathrm{BTC}$ and $1.815 \mathrm{mmol}(0.585 \mathrm{~g}) \mathrm{ZrOCl}_{2} .8 \mathrm{H}_{2} \mathrm{O}$ were weighed in a $10 \mathrm{~mL}$ crimp cap vial. Next, deionized water was added (1.5 mL for MOF-808-TFA and $4.55 \mathrm{~mL}$ for MOF-808-PFPA), followed by $17.8 \mathrm{mmol}$ TFA or PFPA, respectively. The reaction mixture was then stirred in a heating block at $100{ }^{\circ} \mathrm{C}$ for $24 \mathrm{~h}$. In the next step, the MOF particles were washed 3 times with water $(15 \mathrm{~mL})$ and 3 times with ethanol $(15 \mathrm{~mL})$, followed by centrifugation at $4500 \mathrm{rpm}$ for $30 \mathrm{~min}$ after each washing step. Finally, the MOF was dried in a vacuum oven at $70{ }^{\circ} \mathrm{C}$ overnight and stored until further use.

\subsection{Preparation of pristine PDMS based membranes}

Pristine PDMS membranes were prepared by solvent evaporation. Elastosil LR6240A and Elastosil LR6240B (in a mass ratio 1:1) were dissolved in hexane to obtain a solution containing $15 \mathrm{wt} \%$ of polymer. The PDMS solution was stirred for $3 \mathrm{~h}$ at room temperature. Subsequently, an appropriate amount of polymer solution was poured into a stainless steel mold and left for $24 \mathrm{~h}$ at room temperature for the solvent to evaporate. The membrane was then heated in the oven at $80^{\circ} \mathrm{C}$ for $2 \mathrm{~h}$ to achieve the final crosslinking [44]. 


\subsection{Preparation of filled PDMS based membranes}

Filled PDMS based membranes were prepared by adding an appropriate amount of MOF-808 to the PDMS solution to obtain the amount of fillers corresponding to 5, 10 or $15 \mathrm{wt} \%$ of the polymer. Subsequently, the PDMS/MOF-808 solution was mixed for $24 \mathrm{~h}$ and sonicated for 15 min. Membrane casting and crosslinking was performed according to the procedure used for the pristine films.

\subsection{Material characterization of MOF-808 and PDMS based membranes}

SEM analysis was performed applying LEO 1430 VP microscope (Leo Electron Microscopy Lrd., Cambridge, UK) at $30 \mathrm{keV}$. Membranes were sputtered with a conductive layer of $\mathrm{Au} / \mathrm{Pd}$ (the composition of layer 80/20).

TEM analysis was determined using Tecnai F20 X-Twin (FEI Europe B.V, Eindhoven, The Netherlands). Powder suspension of MOFs in ethanol was placed on the copper mesh and positioned in the holder.

XRD analysis was recorded on Philips X'Pert in a transmission mode over a $5-80^{\circ} 2 \theta$ range using $\mathrm{X}^{\prime}$ Celerator Scientific detector with $\mathrm{Cu}$ anode.

AFM analysis in a tapping mode was completed with NanoScope MultiMode SPM system (Veeco Digital Instrument Plainview, USA). Results were analysed using Nanoscope v6.13 software (Bruker Optik GmbH, Ettlingen, Germany). The roughness parameter is an average of 5 measurements, and the scanned area was equal to $5 \mu \mathrm{m} \times 5 \mu \mathrm{m}$.

TGA analysis was accomplished using TGA-DTA Thermal Analysis TA Instruments type SDT 2960 (TA Instrument, Champaign, USA). Measurements were performed under a nitrogen atmosphere, in the temperature range of $25^{\circ} \mathrm{C}-950^{\circ} \mathrm{C}$ with the heating rate equal to $10^{\circ} \mathrm{C} / \mathrm{min}$. Obtained results were analysed using TA Universal Analysis v5.5.24 software (TA Instrument, Champaign, IL, USA).

Gemini VI (Micromeritics Instrument Corp., Norcross, USA) was used to determine the nitrogen adsorption/desorption analysis. Prior to the analysis, samples were degassed at $110^{\circ} \mathrm{C}$ for $6 \mathrm{~h}$. Experiments were conducted at $-195.7^{\circ} \mathrm{C}$. The surface areas were calculated using the BET (Brunauer-Emmett-Teller) model.

Contact angle (CA) measurements were accomplished using the Goniometer Attention Theta (Biolin Scientific, Gothenburg, Sweden) and the room temperature and equilibration time equal to $5 \mathrm{sec}$. Water (drop volume equal to $4 \mu \mathrm{l}$ ) and glycerol (drop volume equal to $2 \mu \mathrm{l}$ ) were 
selected as tested liquids. Results were analysed using OneAttention v2.8 r5543 software (Biolin Scientific, Gothenburg, Sweden) allowing to calculate the surface free energy (SFE) based on the Owens-Wendt method [36].

Litsizer ${ }^{\mathrm{TM}} 500$ (Anthon Paar, Graz, Austria) was implemented for the determination of the particle size distribution of MOFs. Results were analysed using the Kalliope ${ }^{\mathrm{TM}}$ v2.10.5 software (Anthon Paar, Graz, Austria).

The thickness of the prepared membranes was measured with the Sylvac type S 229 thickness gauge (Sylvac, Yverdon-les-Bains, Switzerland) with a resolution of $0.001 \mathrm{~mm}$ and an accuracy of $0.002 \mathrm{~mm}$. The average thickness of the membrane was calculated from 21 measurements over the membrane surface.

\subsection{Uptake degree}

Membrane samples were weighed, immersed in solvents and after of given period of time weighed again. The procedure was repeated until the constant weight of membrane samples was achieved. The uptake degree was determined using Eq. (10) [45]:

$$
U P=\frac{W_{s}-W_{d}}{W_{d}} 100 \%
$$

where $W_{s}$ and $W_{d}$ are masses of swollen and dry membrane samples, respectively.

\subsection{Pervaporation experiments}

Pervaporation experiments were performed using a standard laboratory rig. Laboratory set up and the procedure of pervaporation experiment are described in detail in our previous work [41]. The active membrane area was equal to $14.5 \mathrm{~cm}^{2}$. Mixtures of organic solvents (ethyl acetate/ethanol, ethyl acetate/isopropanol, ethyl tert-butyl ether/ethanol) were used as feed mixtures at the following mass ratios: 20/80, 40/60, 50/50, 60/40 and 80/20. Pervaporation experiments were performed at $30^{\circ} \mathrm{C}$.

Transport properties of tested membranes were evaluated using total flux $\left(J_{t}\right)$ and partial permeate fluxes $\left(J_{i}\right)$, whereas the membrane separation efficiency was estimated using separation factor $(\beta)$ and thickness normalised Pervaporation Separation Index $\left(P S I_{N}\right)$.

Total flux was determined based on Eq. (11) [45]:

$J_{t}=\frac{\Delta m}{A \cdot \Delta t}$

where $\Delta m$ is a mass of permeate collected over $\Delta \mathrm{t}$ time, $A$ is a membrane's active area. 
Partial permeate flux of component $i$ of separated mixture was calculated using Eq. (12) [45]:

$J_{i}=J_{t} \cdot y_{i}$

where $y_{i}$ is a mass fraction of component $i$ in permeate.

The separation factor was calculated using Eq. (13) [45]:

$\beta=\frac{y_{i} /\left(1-y_{i}\right)}{x_{i} /\left(1-x_{i}\right)}$

where $y_{i}$ and $x_{i}$ are the mass fractions of component $i$ in the permeate and in the feed, respectively.

The thickness normalised Pervaporation Separation Index (Eq. (14)) was used to compare the efficiency of various membranes during the pervaporation separation [44].

$P S I_{N}=l \cdot J_{t} \cdot(\beta-1)$

where $l$ is a thickness of the membrane selective layer $[\mu \mathrm{m}]$.

The composition of feed and permeate samples were determined using gas chromatography methods. The analysis was performed using the Varian 3300 gas chromatograph (Varian, Palo Alto, USA) with TCD detector and Porapack Q packed column. Results were analysed using the Borwin v1.21.07 software (JMBS, Grenoble, France).

The accuracy of gas chromatography analysis was estimated by determining the value of LOD (limit of detection) and LOQ (limit of quantification) [41, 46]. LOD is a concentration at which signal-to-noise $(\mathrm{S} / \mathrm{N})$ is equal to 3 , whereas LOQ calculations were performed at $\mathrm{S} / \mathrm{N}=10$. The obtained value of LOD and LOQ are gathered in Table 3.

Table 3. LOD and LOQ for investigated organic solvents.

\begin{tabular}{lcc}
\hline Solvent & LOQ [\%] & LOD [\%] \\
\hline EtAc & 0.05 & 0.14 \\
ETBE & 0.16 & 0.20 \\
EtOH & 0.03 & 0.09 \\
IPA & 0.10 & 0.26 \\
\hline
\end{tabular}




\section{Results and discussion}

\subsection{Characterization of MOF particles}
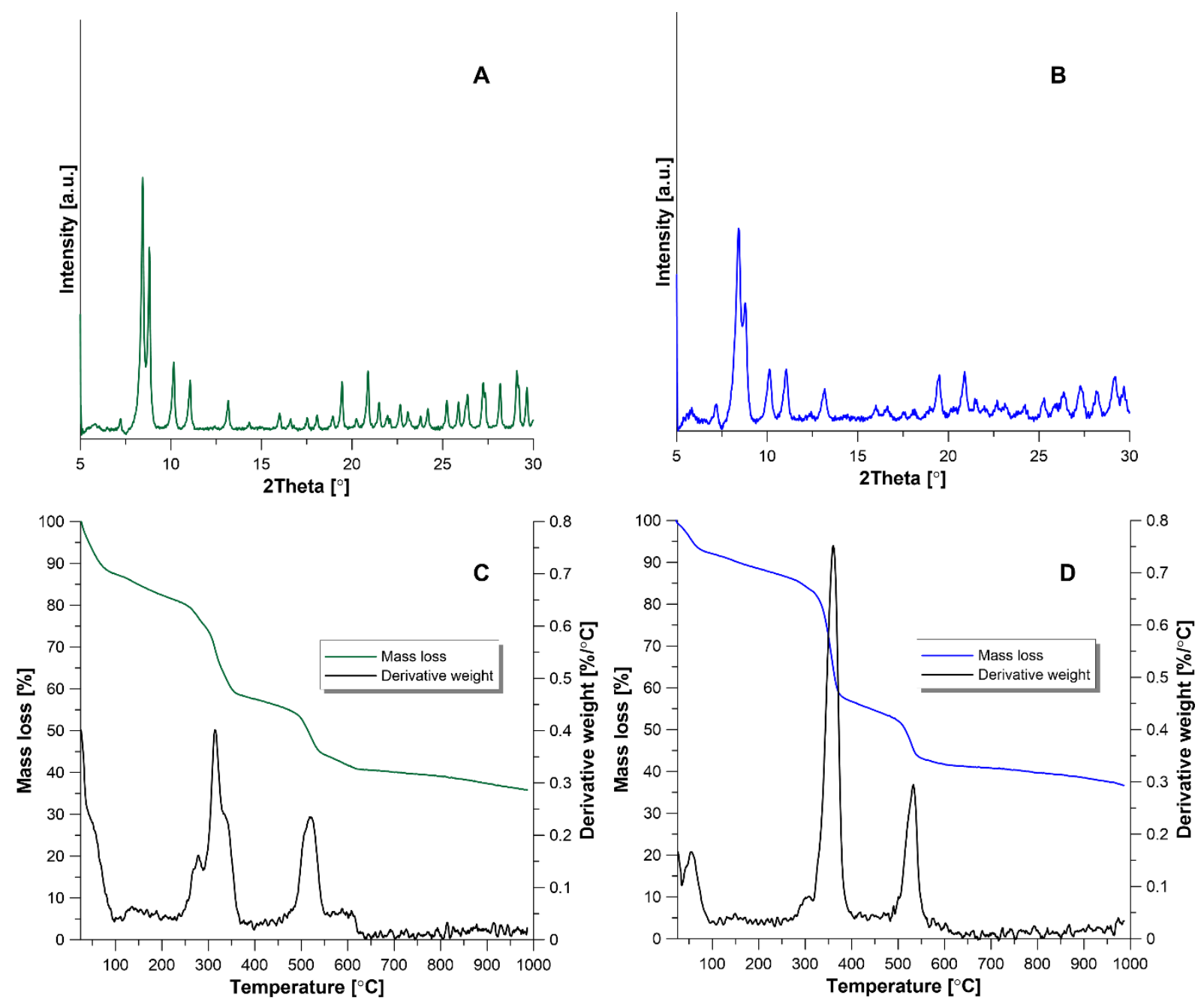

Figure 1. XRD patterns of MOF-808-TFA (A) and MOF-808-PFPA (B) and TGA curves of MOF808-TFA (C) and MOF-808-PFPA (D).

Figure 1A and B present the XRD pattern of MOF-808-TFA and MOF-808-PFPA. All diffraction peaks can be well-indexed, which means that the synthesised MOFs possess a highly crystalline structure. The peaks at $2 \theta=8.32^{\circ}$ and $8.69^{\circ}$ were assigned to diffraction from the planes (311) and (222) of MOF-808, respectively [47]. The high crystallinity was confirmed by the presence of very sharp peaks. However, a slightly higher level was found for the MOF-808-TFA. Moreover, no additional diffraction peaks were noticed. This observation proved that the procedure applied for MOF synthesis allows to obtain highly crystalline structures without impurities.

TGA and DTG analysis were performed to determine the thermal stability of MOF-808-TFA and MOF-808-PFPA (Figure 1C and D). The first mass loss below $100^{\circ} \mathrm{C}$ is related to the evaporation of modulators TFA and PFPA. The boiling point of TFA and PFPA 
is to $71.8^{\circ} \mathrm{C}$ and $96.5[48,49]$. Mass loss in the temperature range of $200-250^{\circ} \mathrm{C}$ (in the case of MOF-808-PFPA, $200-350^{\circ} \mathrm{C}$ ) corresponds to the removal of ligands. Further increase of temperature, from $300^{\circ} \mathrm{C}$ to $650^{\circ} \mathrm{C}$, results in BTC linker loss and the framework collapse [50]. Observed weight loss indicates that the final degradation product of MOF-808 is zirconium oxide $[50,51]$. Moreover, based on DTG curves, it can be concluded that the degradation of TFA and PFPA modifiers occurs in the range of $250-400^{\circ} \mathrm{C}$ (Figure $1 \mathrm{C}$ and $1 \mathrm{D}$ ).
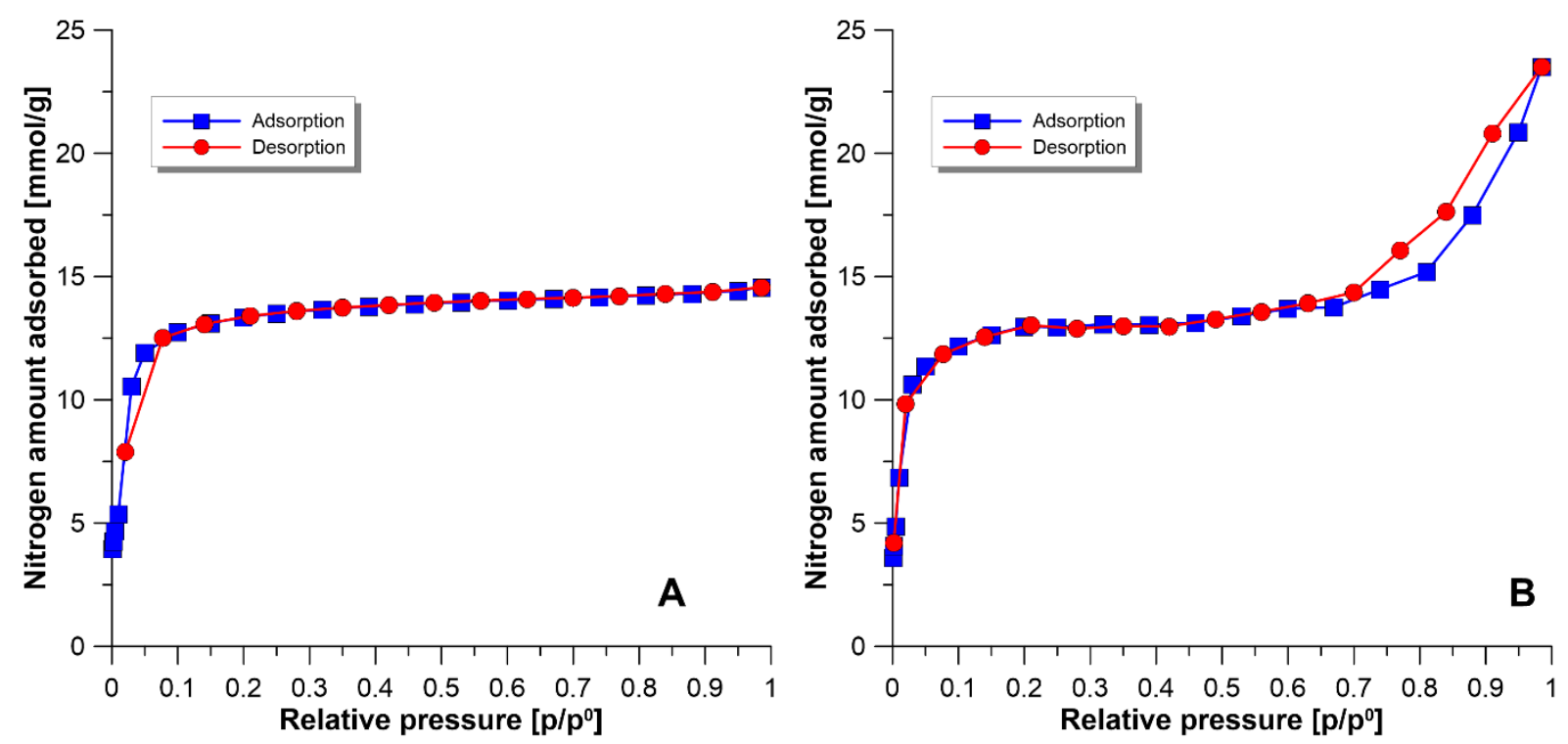

Figure 2. $\mathrm{N}_{2}$ adsorption isotherm of MOF-808-TFA (A) and MOF-808-PFPA (B).

Figure 2 presents the adsorption isotherm of MOF-808-TFA and MOF-808-PFPA. The obtained adsorption isotherm can be classified as type I according to the UIPAC classification [52] and are in the good agreement with literature data [53-55]. The sharp increase in the value of nitrogen adsorbed in the relative pressure range from 0 to 0.05 results from the filling of micropores. Subsequently, the isotherm passes through the plateau. In the case of MOF-808-TFA, the hysteresis loop and a small slope at $\mathrm{p} / \mathrm{p}^{0}$ close to unity are observed, which confirms the absence of mesopores (Figure 2A). A different situation was noticed for the MOF-808-PFPA. In this case, the hysteresis loop was detected, which could indicate the presence of mesopores (Figure 2B).

Determined BET surface area, pore size, and pore volume are summarised in Table 4. Compared to the literature data, the modification of MOF-808 with TFA and PFPA leads to a decrease in the surface area, pore size, and pore volume. A similar observation was found by Liu et al. [56]. The authors observed the reduction of BET surface area (from $2152 \mathrm{~m}^{2} \mathrm{~g}^{-1}$ to $1899 \mathrm{~m}^{2} \mathrm{~g}^{-1}$ ) and pore size (from $17.1 \mathrm{~nm}$ to $13.6 \mathrm{~nm}$ ) after modification of MOF-808 by the introduction of amidoxime functional groups on the surface [56]. Considering 
the modulators, a reduction of parameters was noticed along with the lengthening of the alkyl chain. Moreover, it should be mentioned that MOF-808-TFA and MOF-808-PFPA showed higher surface area, pore size, and pore volume than the similar UiO-66, which extends the range of potential application of MOF-808-TFA and MOF-808-PFPA.

Table 4. BET surface area, average pore size, and pore volume of MOF-808-TFA, MOF-808-PFPA, and literature data.

\begin{tabular}{lccc}
\hline \multicolumn{1}{c}{ Materials } & BET $\left[\mathbf{m}^{\mathbf{2}} \mathbf{~ g}^{-1}\right.$ ] & Pore size $[\AA]$ & Pore volume $\left[\mathbf{c m}^{\mathbf{3}} \mathbf{~ g}^{-1}\right]$ \\
\hline UiO-66 [57] & 1050 & 6.0 & 0.54 \\
MOF-808 [58] & 2060 & 18.4 & 0.84 \\
MOF-808-TFA & 1189 & 18.3 & 0.56 \\
MOF-808-PFPA & 1069 & 15.4 & 0.50 \\
\hline
\end{tabular}

TEM, SEM, and DLS techniques were used for characterisation of obtained MOF-808 particles. Results proved the formation of characteristic octahedral crystals (Figure 3A and B) with particle size in the range of 460-580 nm for MOF-808-TFA and 60-90 nm for MOF-808-PFPA. Additionally, DLS analysis showed that the average size of the particles for MOF-808-TFA and MOF-808-PFPA was equal to $460 \pm 10 \mathrm{~nm}$ and $60 \pm 10 \mathrm{~nm}$, respectively (Figure 3C and D). Based on the TEM data, it was possible also to discuss the crystallinity of the generated materials. Taking into account the XRD data and TEM images, a slightly higher crystallinity of the MOF-808-TFA has been found. TEM images showed a powder composed of agglomerated fine particles for the MOF-808-PFPA sample, which possessed a bit lower crystallinity. This statement was proved by the appearance of broader peaks in the range of 2 theta 5 to $12.5^{\circ}$. Such broadening and the lower intensity of the diffraction peaks is typical for lower crystallinity [59-61]. 

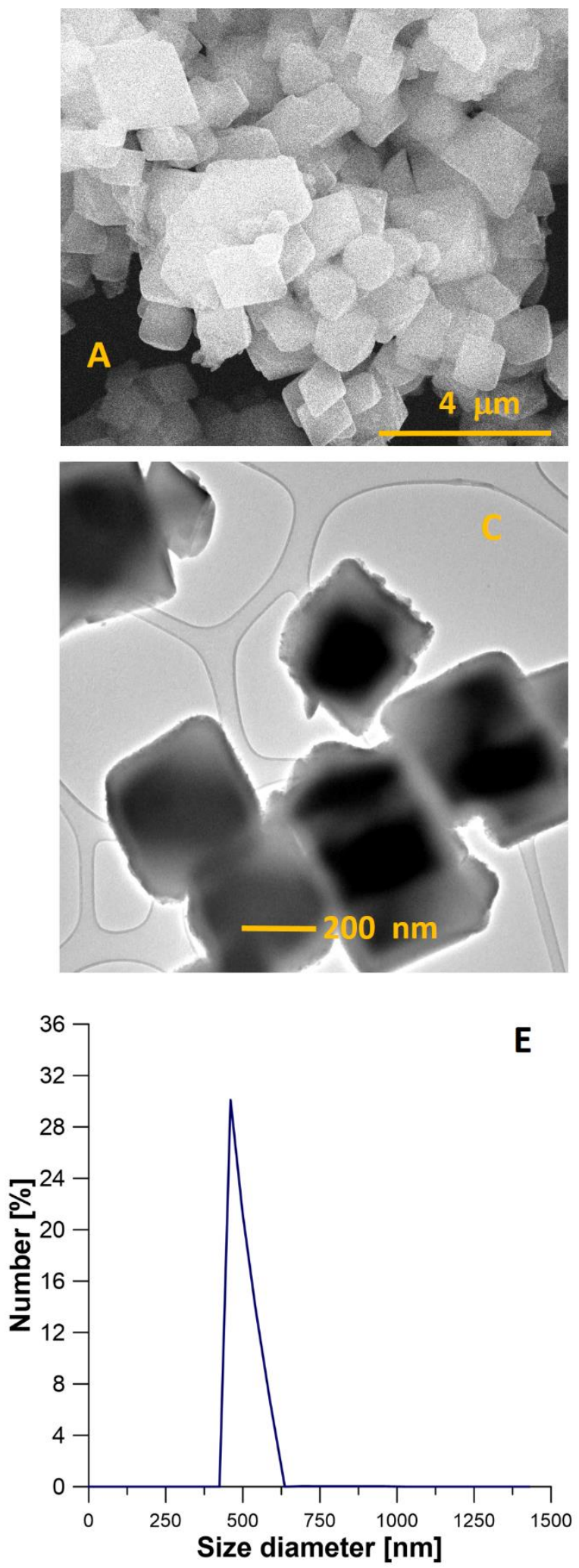
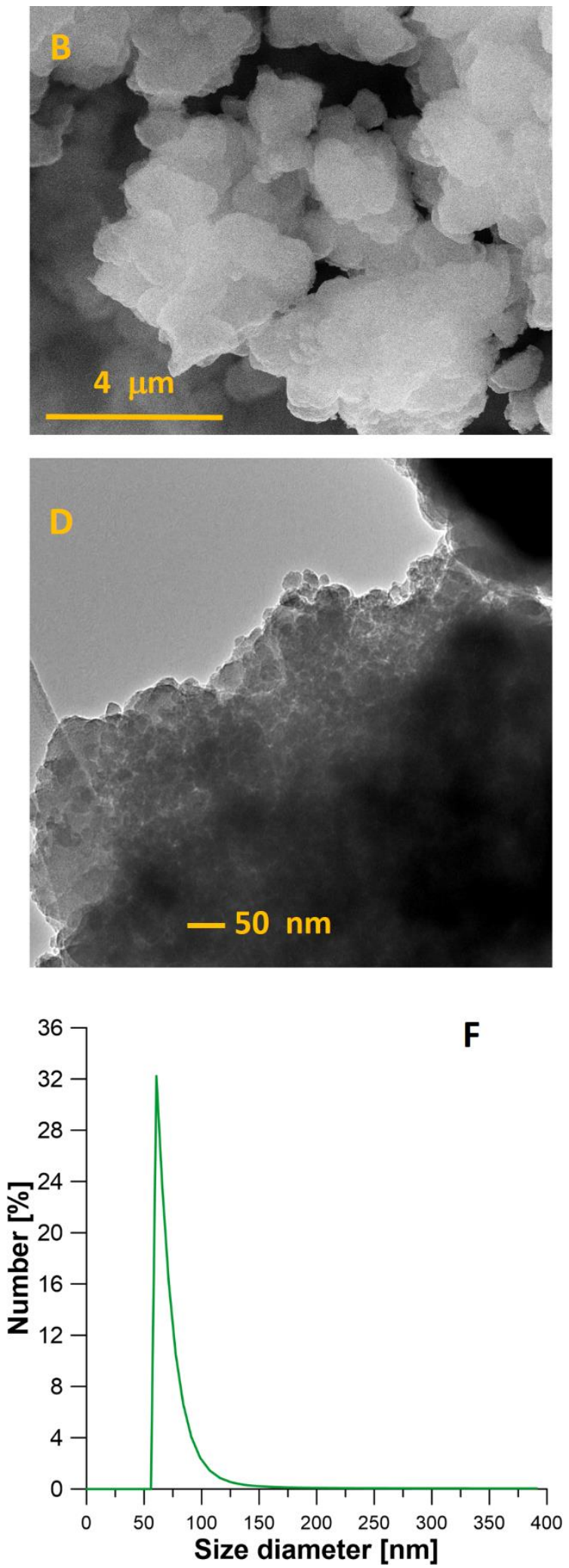

Figure 3. SEM and TEM micrograph of MOF-808-TFA (A and C), MOF-808-PFPA (B and D), and DLS results for MOF-808-TFA (E) and MOF-808-PFPA (F). 


\subsection{Characterization of membranes}

Morphology, thermal stability, and surface properties of prepared membranes were analysed using SEM, AFM, TGA, and contact angle measurement. It should be noted that in the case of PDMS/MOF-808-PFPA membranes, the maximum filler content in polymer matric was $10 \mathrm{wt} \%$. Above this value, MOF-808-PFPA interacted excessively with the platinum catalyst, which prevented the crosslinking process.
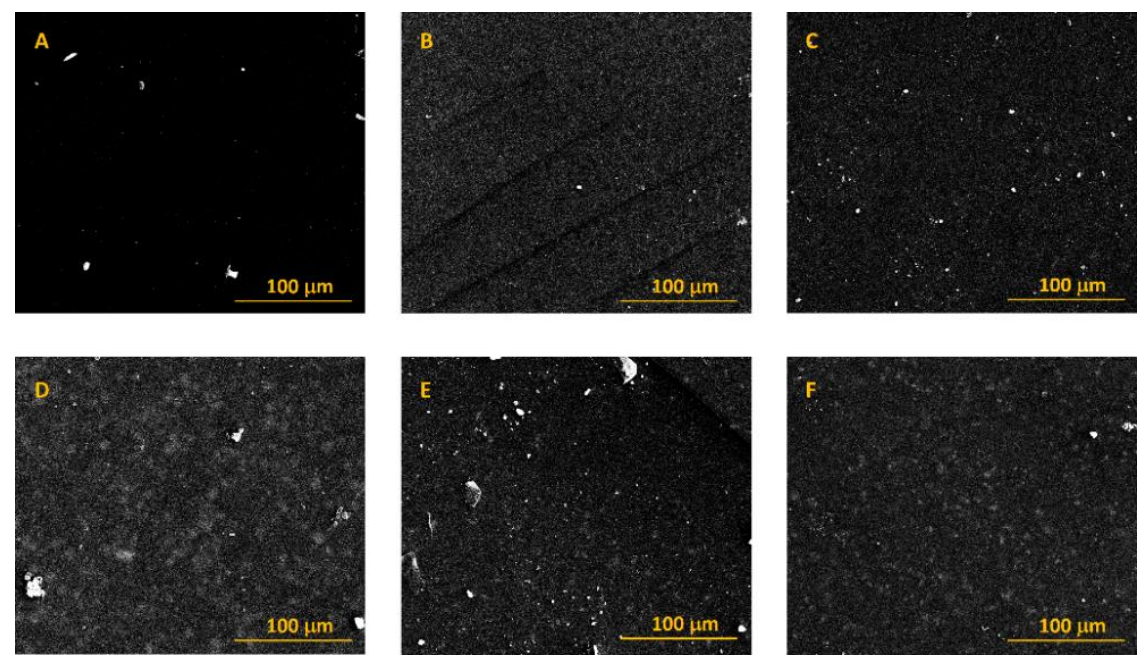

Figure 4. SEM micrographs of pristine PDMS (A), PDMS/MOF-808-TFA (5 wt.\%) (B), PDMS/MOF808-TFA (10 wt\%) (C), PDMS/MOF-808-TFA (15 wt\%) (C), PDMS/MOF-808-PFPA (5 wt\%) (E), and MOF-808-PFPA (10 wt $\%)(F)$ membranes.

SEM analysis proved the formation of dense non-porous membranes (Figure 4A). In the case of filled membranes, the surface of the membranes is characterised by the even distribution of particles in the polymer matrix (Figure 4A-F). As can be seen, MOF particles are well dispersed, only small agglomerates can be visible.

Surface topography of the prepared membranes was evaluated using Atomic Force Microscopy (AFM). Obtained results are presented in Table 5 and Figure 5. The smallest $R_{A}$ value $(7.3 \mathrm{~nm})$ was found for the pristine PDMS membrane. The presence of the fillers slightly increased the roughness $R_{A}$ of the membranes to $9.5 \mathrm{~nm}$ for the PDMS/MOF-808-TFA (10 wt $\%$ ) membrane (Table 5). 
Table 5. Values of roughness average parameter $R_{A}$ of PDMS based membranes.

\begin{tabular}{lc}
\hline Membranes & $\boldsymbol{R}_{A}[\mathbf{n m}]$ \\
\hline PDMS pristine & $7.3 \pm 0.8$ \\
PDMS/MOF-808-TFA $(\mathbf{5}$ wt \%) & $7.7 \pm 0.7$ \\
PDMS/MOF-808-TFA $(\mathbf{1 0}$ wt \%) & $9.5 \pm 1.0$ \\
PDMS/MOF-808-TFA (15 wt\%) & $9.3 \pm 0.9$ \\
& \\
PDMS/MOF-808-PFPA (5 wt \%) & $11.5 \pm 1.7$ \\
PDMS/MOF-808-PFPA (10 wt \%) & $11.8 \pm 0.7$ \\
\hline
\end{tabular}
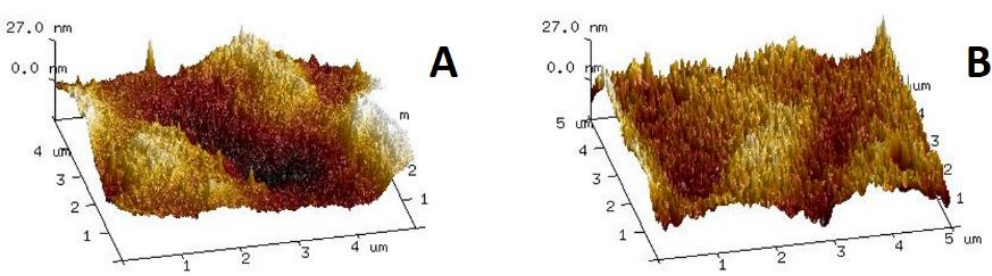

B
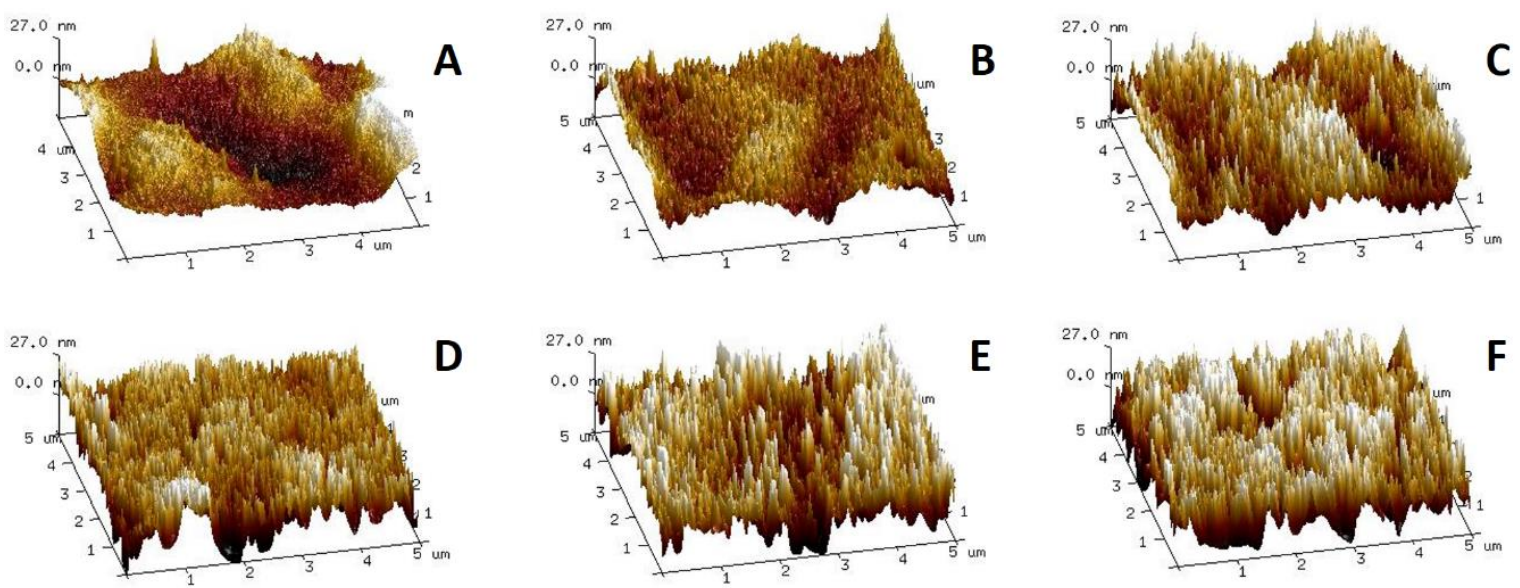

D
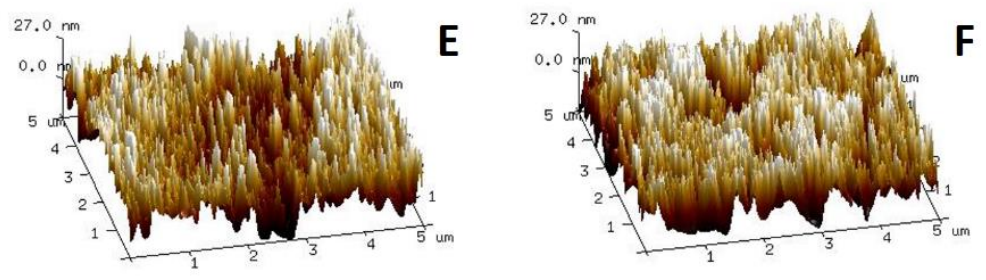

Figure 5. AFM images of A-pristine PDMS, B-PDMS/MOF-808-TFA (5 wt $\%$ ), C-PDMS/MOF-808-TFA (10 wt\%), D-MOF-808-TFA (15 wt\%), E-PDMS/MOF-808-PFPA (5 wt $\%$ ), and F-PDMS/MOF-808-PFPA (10 wt\%) membranes.

Additionally, it was observed that the increase of the MOF-808-TFA content in the polymer from $10 \mathrm{wt} \%$ to $15 \mathrm{wt} \%$ does not influence of surface roughness of the filled membranes. The opposite situation was detected for MOF-808-PFPA, in that case, MMMs showed a higher value of $R_{A}$ than for the pristine PDMS membrane (Table 5). This might be related to the smaller size of MOF-808-PFPA. Moreover, this MOF showed a higher tendency to aggregation compared with MOF-808-TFA [22]. A similar observation was found by Shen et al. [16]. The higher value of the $R_{A}$ parameter for membranes containing MOF-808-PFPA compared to those containing MOF-808-TFA can be explained by the lower compatibility of MOF-808-PFPA with the non-fluorinated polymer matrix. The compatibility between MOF particles and polymer matrix is a crucial parameter that should be considered during the selection of MOF particles. Compatibility affects not only the membrane morphology but also the separation properties of MMM.

The surface character of the membranes was also investigated by measuring the contact angle of water and glycerol with the membranes and then calculating the surface free energy. 

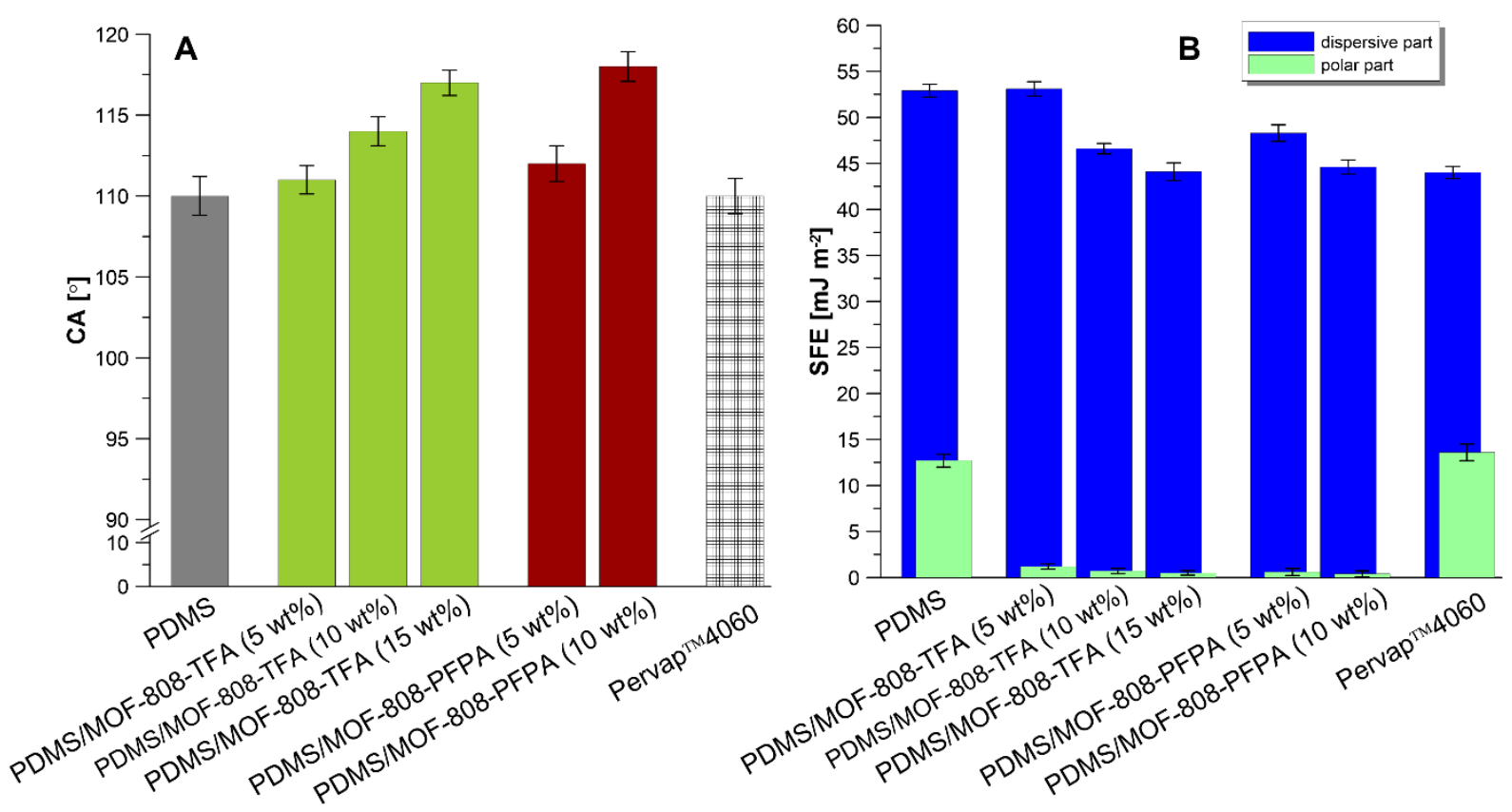

Figure 6. The apparent contact angle (CA) of water (A) and surface free energy (B) for pristine and filled PDMS based membranes.

Figure 6A presents the contact angle of water with the membranes. All prepared membranes in this research possess hydrophobic character as the obtained values of the contact angle of water are higher than $90^{\circ}$.

The incorporation of MOF particles into a membrane matrix increases the water contact angle. An additional increase of $C A$ was observed for the membrane with a higher MOF content. The highest $C A$ values, found for PDMS/MOF-808-TFA (15 wt\%) and PDMS/MOF-808-PFPA (10 wt $\%$ ), were $112^{\circ}$ and $114^{\circ}$, respectively. Comparing the MOF particles, a higher $C A$ was noticed for membranes modified with MOF-808-PFPA (Figure 6A). This observation is related to the more hydrophobic character of the particles. The $C A$ for Pervap 4060 was $111^{\circ}$. Kujawska et al. [44] measured the contact angle for pristine PDMS and Pervap 4060 membranes. In their research, a similar value of contact angle of water for Pervap $4060\left(108^{\circ}\right)$ was observed. In the case of pristine PDMS membranes, authors obtained a higher value for CA, equal to $114^{\circ}$ [44]. It should also be mentioned that the obtained contact angle for pristine PDMS membrane $\left(110^{\circ}\right)$ is within the range determined by Owen and Dvornic $\left(110^{\circ}-120^{\circ}\right)$ [62].

Figure $6 \mathrm{~B}$ presents the calculated surface free energy for tested membranes. As can be seen, the incorporation of MOF particles changes the value of the surface free energy of the membranes. The polar part of the SFE decreased for filled membranes compared with pristine PDMS membranes. Further decrease of the polar part of the surface free energy 
was noticed by increasing the amount of MOF particles in the polymer matrix. This observation proved that the incorporation of MOF-808 causes an increasing hydrophobic character of membranes. Considering the type of modifier (TFA and PFPA), a higher SFE was observed for MOF-808-TFA. Membranes modified by MOF-808-PFPA showed a higher contact angle for water compared to PDMS/MOF-808-TFA.
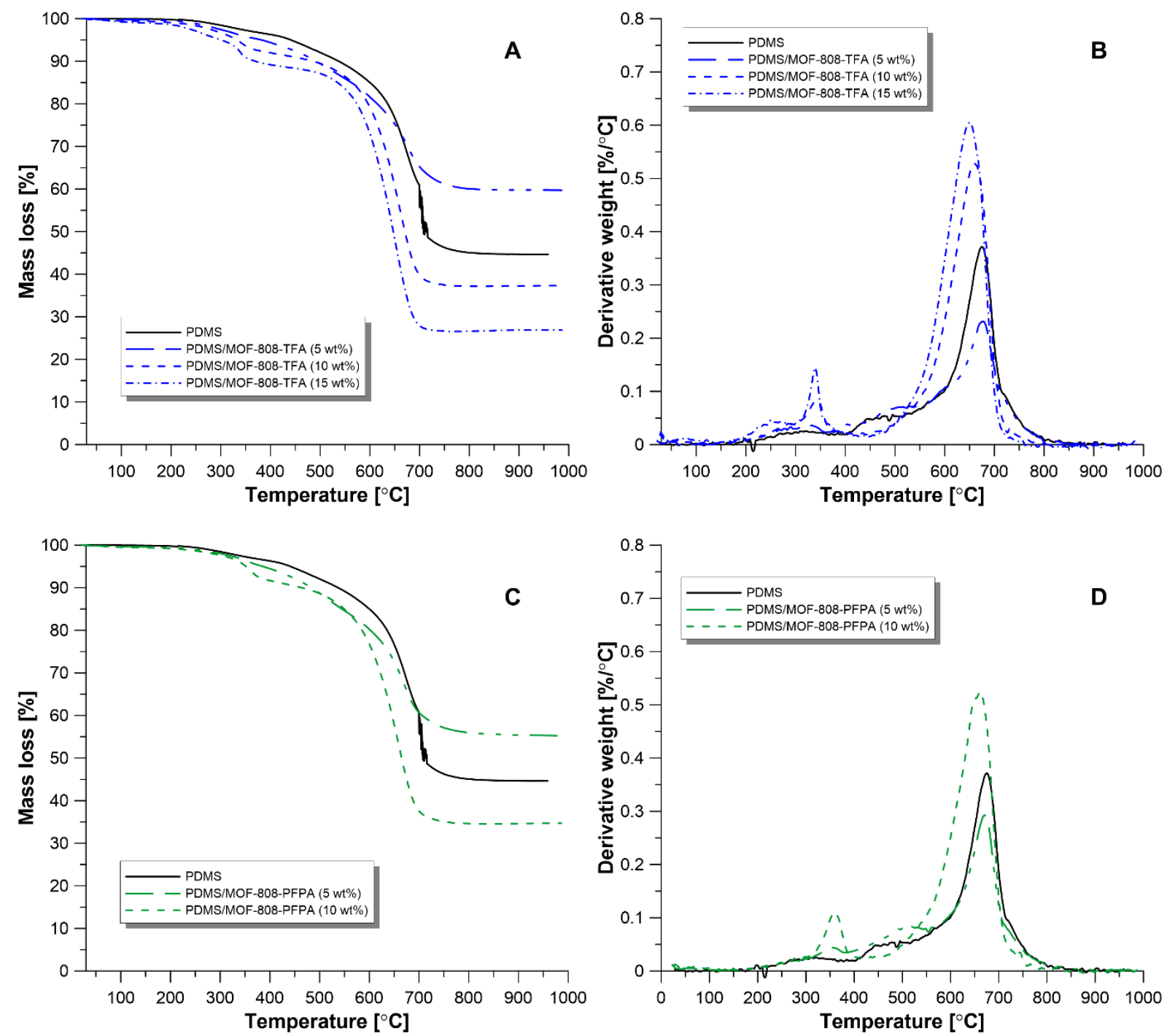

Figure 7. Thermogravimetric analysis PDMS/MOF-808-TFA membranes (A and B), and PDMS/MOF-808-PFP membranes (C and D).

The influence of incorporation of MOF particles in the membrane matrix on thermal properties was determined using thermogravimetric analysis. The obtained results were presented in Figure 7. Degradation of the PDMS membrane occurs in one stage, and the membrane is thermally stable up to $400^{\circ} \mathrm{C}$ (Figure 7). In this case, during the degradation, the polymer chain breaks down, and the cyclic hexamethylcyclotrisiloxane is formed [63]. In the case of filled membranes, incorporation of MOF particles causes a decrease of thermal 
stability. The degradation of PDMS/MOF-808-TFA and PDMS/MOF-808-PFPA membranes starts from $340^{\circ} \mathrm{C}$ and $360^{\circ} \mathrm{C}$, respectively (Figure 7A and C). This observation is related to the lower stability of MOFs. TGA analysis of MOF-808-TFA and MOF-808-PFPA proved that those particles are thermally stable up to $300^{\circ} \mathrm{C}$ and $350^{\circ} \mathrm{C}$, respectively (Figure $7 \mathrm{C}$ and D). Moreover, comparing the DTG curves, it was noticed that the intensity of peaks at $350^{\circ} \mathrm{C}$ and $650^{\circ} \mathrm{C}$ increase with increasing content of MOFs in the polymer matrix (Figure 7B and D).

\subsection{Hansen's Solubility Parameter}

To forecast and describe the interaction between separated system and membrane material, the of Hansen's Solubility Parameters approach was implemented (Section 2.2).

NMR and TGA analysis were used to determine the structural formulas of MOF-808-TFA and MOF-808-PFPA [22]. Obtained results allow to estimate the average number of ligands in the cluster. The determined structural formulas of MOF-808-TFA and MOF-808-PFPA are equal to $\mathrm{Zr}_{6} \mathrm{O}_{4}(\mathrm{OH})_{4} \mathrm{BTC}_{2}(\mathrm{TFA})_{4.9}(\mathrm{OH})_{1.1}$ and $\mathrm{Zr}_{6} \mathrm{O}_{4}(\mathrm{OH})_{4} \mathrm{BTC}_{2}(\mathrm{PFPA})_{4.2}(\mathrm{OH})_{1.8}$, respectively [22].

Due to the lack of HSP for PFPA in the literature, it was decided to determine solubility parameters for unmodified MOF-808. Table 6 presents the modified HSP for PDMS/MOF-808 membranes. The modified HSP for filled membranes were calculated using Eq. (8).

Table 6. Hansen's Solubility Parameters for PDMS based membranes.

\begin{tabular}{lccc}
\hline \multirow{2}{*}{ Membranes } & \multicolumn{3}{c}{ Hansen's Solubility Parameters [MPa $\left.{ }^{\mathbf{0} 5}\right]$} \\
\cline { 2 - 4 } & $\delta_{d}$ & $\delta_{p}$ & $\delta_{h}$ \\
\hline PDMS & 15.9 & 0 & 4.1 \\
PDMS/MOF-808 (5 wt\%) & 16.1 & 0.5 & 4.8 \\
PDMS/MOF-808 (10 wt\%) & 16.3 & 0.9 & 5.4 \\
PDMS/MOF-808 (15 wt\%) & 16.6 & 1.4 & 6.0 \\
\hline
\end{tabular}

Table 7. The distance parameters between PDMS based membranes and pure solvents, calculated according to the Eq. (7).

\begin{tabular}{lcccc}
\hline \multirow{2}{*}{ Membranes } & EtOH & IPA & EtAc & ETBE \\
\cline { 2 - 5 } & \multicolumn{4}{c}{$\Delta\left[\mathbf{M P a} \mathbf{0}^{\mathbf{0}}\right]$} \\
\hline PDMS & 17.7 & 13.7 & 6.1 & 2.4 \\
PDMS/MOF-808 (5 wt\%) & 16.9 & 12.9 & 5.4 & 2.3 \\
PDMS/MOF-808 (10 wt\%) & 16.1 & 12.2 & 4.8 & 2.1 \\
PDMS/MOF-808 (15 wt\%) & 15.3 & 11.4 & 4.1 & 2.0 \\
\hline
\end{tabular}


An interaction between prepared membranes and used feed solutions, organic-organic solvents were calculated (Table 7 and 8). Taking into account pure solvents, the strongest interactions (the smallest values of $\Delta$ ) were found for materials contacting ETBE (Table 7). On the other hand, the worst interactions that might reflect sorption feature of the membranes were determined for ethanol. Considering the contact of the MMM with solvents, an interesting observation has been made (Table 7). The distance parameter decreases with the amount of MOF filler in the polymeric matrix. It means that adding MOF to the membrane could enhance the membrane performance in comparison to the pristine PDMS membrane based on sorption only. Furthermore, a mixture possessing higher EtAc levels showed a stronger affinity to these filled membranes, independently on the MOF content (Table 8). Moreover, the membranes showed a higher affinity for EtAc/IPA mixtures compared with EtAc/EtOH mixtures. Taking into account separation materials contacting the ETBE/EtOH system, the strongest interactions between membrane and mixture were found for the 80/20 mixture composition. Moreover, it was the most noticeable interaction among all investigated systems.

Table 8 . The distance parameter $(\Delta)$ calculated according to Eq. (7).

\begin{tabular}{|c|c|c|c|c|c|}
\hline \multirow{2}{*}{ Membranes } & \multicolumn{5}{|c|}{$\Delta\left[\mathbf{M P a}^{0.5}\right]$} \\
\hline & $20 / 80$ & $40 / 60$ & $50 / 50$ & $60 / 40$ & $80 / 20$ \\
\hline \multicolumn{6}{|c|}{ ethyl acetate/ethanol } \\
\hline PDMS & 15.3 & 12.8 & 11.5 & 10.3 & 7.8 \\
\hline PDMS/MOF-808 (5 wt\%) & 14.4 & 12.0 & 10.8 & 9.6 & 7.4 \\
\hline PDMS/MOF-808 (10 wt\%) & 13.6 & 11.2 & 10.0 & 8.9 & 8.1 \\
\hline PDMS/MOF-808 (15 wt\%) & 12.8 & 10.4 & 9.2 & 8.1 & 5.9 \\
\hline \multicolumn{6}{|c|}{ ethyl acetate/isopropanol } \\
\hline PDMS & 12.4 & 10.6 & 9.7 & 8.8 & 7.0 \\
\hline PDMS/MOF-808 (5 wt\%) & 11.2 & 9.6 & 8.8 & 8.0 & 6.6 \\
\hline PDMS/MOF-808 (10 wt\%) & 10.5 & 8.8 & 8.0 & 7.2 & 5.8 \\
\hline PDMS/MOF-808 (15 wt\%) & 9.7 & 8.0 & 7.2 & 6.5 & 5.1 \\
\hline \multicolumn{6}{|c|}{ ethyl tert-butyl ether/ethanol } \\
\hline PDMS & 14.4 & 11.2 & 9.6 & 8.0 & 4.9 \\
\hline PDMS/MOF-808 (5 wt\%) & 13.6 & 10.3 & 8.7 & 7.1 & 4.1 \\
\hline PDMS/MOF-808 (10 wt\%) & 12.8 & 9.6 & 8.0 & 6.5 & 3.5 \\
\hline PDMS/MOF-808 (15 wt\%) & 12.1 & 8.9 & 7.3 & 5.8 & 2.9 \\
\hline
\end{tabular}

Table 9 presents the calculated RED parameter values. Practically all values were higher than 1. All materials were very stable during the contact with the organic mixture. Only in the case of membranes being in contact with ETBE/EtOH, swelling might be observed. For the pristine as well as modified membranes, the value of RED was below 1 . Due to a very strong interaction of the MMM with ETBE and EtAc, an increased amount of this solvent in the feed solution enhances the potential swelling of the membrane. 
Table 9. The RED parameters calculated according to Eq. (9) for tested mixtures and PDMS based membranes.

\begin{tabular}{|c|c|c|c|c|c|}
\hline \multirow[t]{2}{*}{ Membranes } & \multicolumn{5}{|c|}{$R E D$} \\
\hline & $20 / 80$ & $40 / 60$ & $50 / 50$ & $60 / 40$ & $80 / 20$ \\
\hline \multicolumn{6}{|c|}{ ethyl acetate/ethanol } \\
\hline PDMS & 2.7 & 2.2 & 2.0 & 1.8 & 1.4 \\
\hline PDMS/MOF-808 (5 wt\%) & 2.5 & 2.1 & 1.9 & 1.7 & 1.3 \\
\hline PDMS/MOF-808 (10 wt\%) & 2.4 & 2.0 & 1.8 & 1.6 & 1.4 \\
\hline PDMS/MOF-808 (15 wt\%) & 2.3 & 1.8 & 1.6 & 1.4 & 1.0 \\
\hline \multicolumn{6}{|c|}{ ethyl acetate/isopropanol } \\
\hline PDMS & 2.18 & 1.86 & 1.70 & 1.54 & 1.23 \\
\hline PDMS/MOF-808 (5 wt\%) & 1.96 & 1.68 & 1.54 & 1.40 & 1.16 \\
\hline PDMS/MOF-808 (10 wt\%) & 1.84 & 1.54 & 1.40 & 1.26 & 1.02 \\
\hline PDMS/MOF-808 (15 wt\%) & 1.70 & 1.40 & 1.26 & 1.14 & 0.89 \\
\hline \multicolumn{6}{|c|}{ ethyl tert-butyl ether/ethanol } \\
\hline PDMS & 2.5 & 2.0 & 1.7 & 1.4 & 0.9 \\
\hline PDMS/MOF-808 (5 wt\%) & 2.4 & 1.8 & 1.5 & 1.3 & 0.7 \\
\hline PDMS/MOF-808 (10 wt\%) & 2.3 & 1.7 & 1.4 & 1.1 & 0.6 \\
\hline PDMS/MOF-808 (15 wt\%) & 2.1 & 1.6 & 1.3 & 1.0 & 0.5 \\
\hline
\end{tabular}

\subsection{Uptake degree}

Figure 8 presents the results of sorption experiments. The highest upatke degree (UP) was found for membranes in contact with ETBE, and the lowest one for membranes equilibrated with ethanol. It can be assumed that PDMS based membranes should be the most selective towards ETBE, while ethanol should be the least preferentially transported compound through the tested membranes. Moreover, obtained results are in good accordance with calculated distance parameters for pure solvents (Table 7). The calculated distance parameter decreased in the following order: ethanol>isopropanol>ethyl acetate> ethyl tert-butyl ether. Taking into account the influence of incorporation of MOFs on the sorption properties of the membranes, it can be seen that MMMs showed a higher degree of swelling compared to the pristine PDMS membrane. This is a typical behaviour of membranes modified with porous fillers when the sorption capacity for that solvent is higher for the filler than for the polymer material. The porous structure of MOF-808 causes an increase in UP. Compared with pristine PDMS membranes, filled membranes are characterised by a more "porous" structure. Dispersed porous MOF-808 particles provide additional sorption volume for solvents. A similar trend was found by $\mathrm{Si}$ et al. [64]. Incorporation of $3 \mathrm{wt} \%$ of ZIF-8 into a membrane matrix increased the UPvalue for MMM in contact with a solution containing $1.5 \mathrm{wt} \%$ of butanol. Comparing the character of modulators (TFA, PFPA), it was noticed that membranes modified with MOF-808PFPA showed less uptake value. PFPA modulator possesses a more hydrophobic nature compared to TFA. Additionally, it was observed that UP decreased with increasing MOF 
loading in the membrane matrix. As proven by the contact angle measurement and $S F E$ calculation, the incorporation of the MOF particles into the PDMS matrix increases the hydrophobicity of the MMMs. The more hydrophobic character of the membranes results in a lower swelling degree. Xu et al. [65] also observed that the increase UiO-66 content in a poly(imide) matrix reduced the uptake degree for membranes in contact with ethanol, butanol, and isopropanol. This observation can be related to the presence of terephthalic acid in the MOF structure. As a result, the $U P$-value for solvent decreases with increasing UiO-66 loading in the polymer matrix [65].

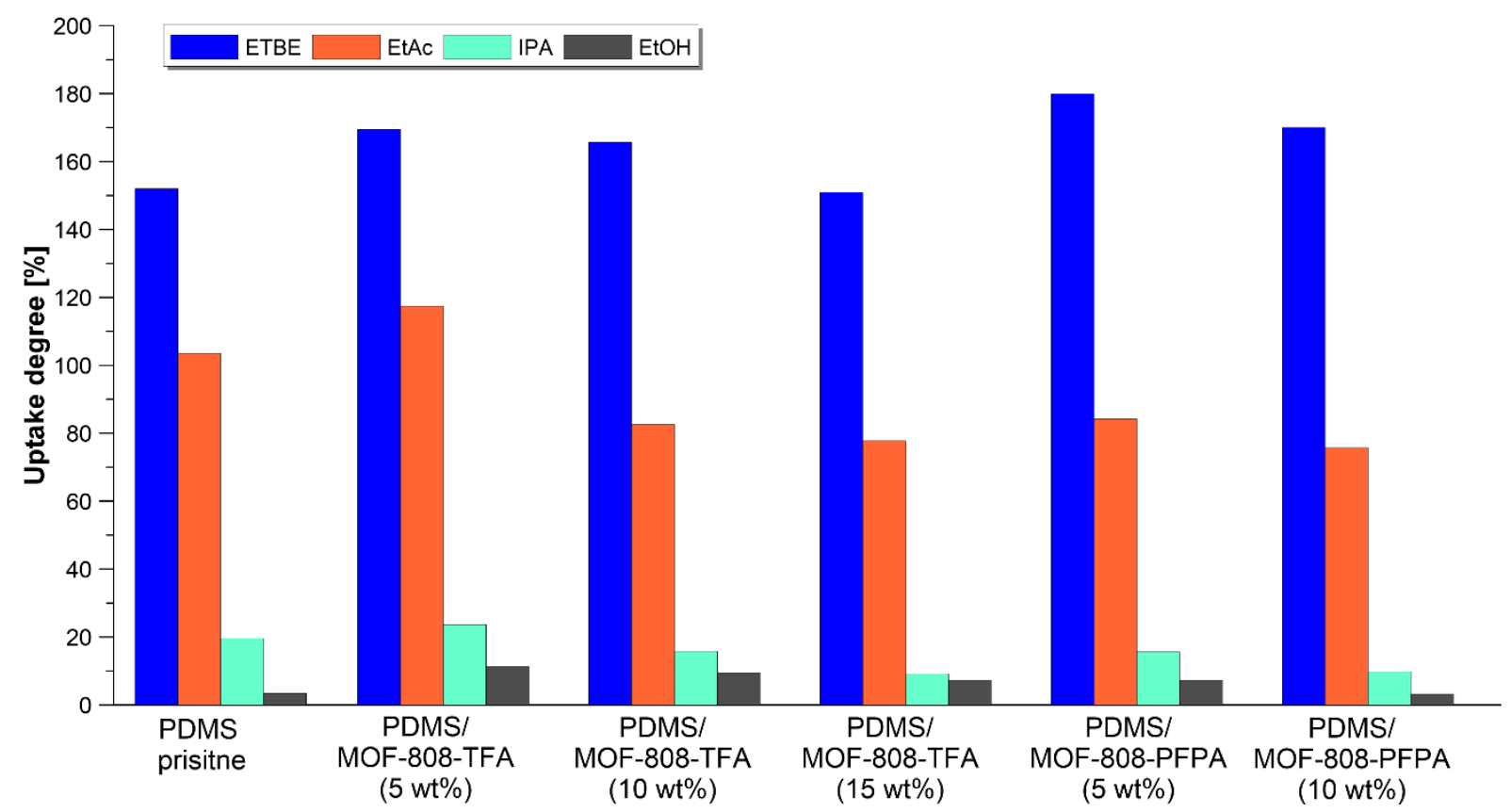

Figure 8. The uptake degree of PDMS based membranes.

\subsection{Pervaporation experiments}

The influence of incorporation of MOF-808-TFA and MOF-808-PFPA into PDMS based membranes on the transport and separation properties was investigated by performing pervaporative separation of ethyl acetate/ethanol, ethyl acetate/isopropanol, and ethyl tert-butyl ether/ethanol mixtures. The efficiency of PDMS based membranes was evaluated using separation factor and thickness normalised Pervaporation Separation Index. The thickness of the tested membranes is presented in Table 10.

Table 10. The thickness of a selective layer of tested membranes. 


\begin{tabular}{|c|c|}
\hline Membranes & Thickness of selective layer $[\mu \mathrm{m}]$ \\
\hline PDMS & $332.2 \pm 5.9$ \\
\hline PDMS/MOF-808-TFA (5 wt \%) & $315.5 \pm 9.7$ \\
\hline PDMS/MOF-808-TFA (10 wt\%) & $384.5 \pm 12.9$ \\
\hline PDMS/MOF-808-TFA (15 wt\%) & $307.8 \pm 6.8$ \\
\hline PDMS/MOF-808-PFPA (5 wt\%) & $349.3 \pm 10.2$ \\
\hline PDMS/MOF-808-PFPA (10 wt\%) & $313.2 \pm 11.1$ \\
\hline Pervap $^{\mathrm{TM} 4060}$ & $6.0 \pm 0.5[66]$ \\
\hline
\end{tabular}

Figure 9A-C present the McCabe-Thiele separation diagram for chosen membranes obtained during the separation of ETBE/EtOH, EtAc/EtOH, EtAc/IPA mixtures. In the case of ETBE/EtOH mixtures, it was found that both laboratory and commercial membranes selectively transported ethyl tert-butyl ether (Figure 9A), while during the separation of EtAc/EtOH and EtAc/IPA, all tested membranes were selective towards ethyl acetate (Figure 9B and C). These results are also in good agreement with the calculated distance parameters (Table 7).

Comparing the data obtained during the separation of ethyl acetate/ethanol and ethyl acetate/isopropanol, a higher concentration of ethyl acetate in the permeate was noticed for ethyl acetate/ethanol. The distance parameter between PDMS and isopropanol was lower than between ethanol and PDMS (Table 7). Moreover, obtained uptake experiments showed that the higher uptake value was observed in contact with isopropanol (Figure 8). That means, in the case of the second component (ethanol or isopropanol) of separated mixtures, transport of isopropanol molecules (due to the higher affinity towards membranes) is more facilitated through the membrane compared with the transport of ethanol molecules. As a result, the lower separation efficiency of PDMS based membranes during the separation of EtAc/IPA was obtained. 

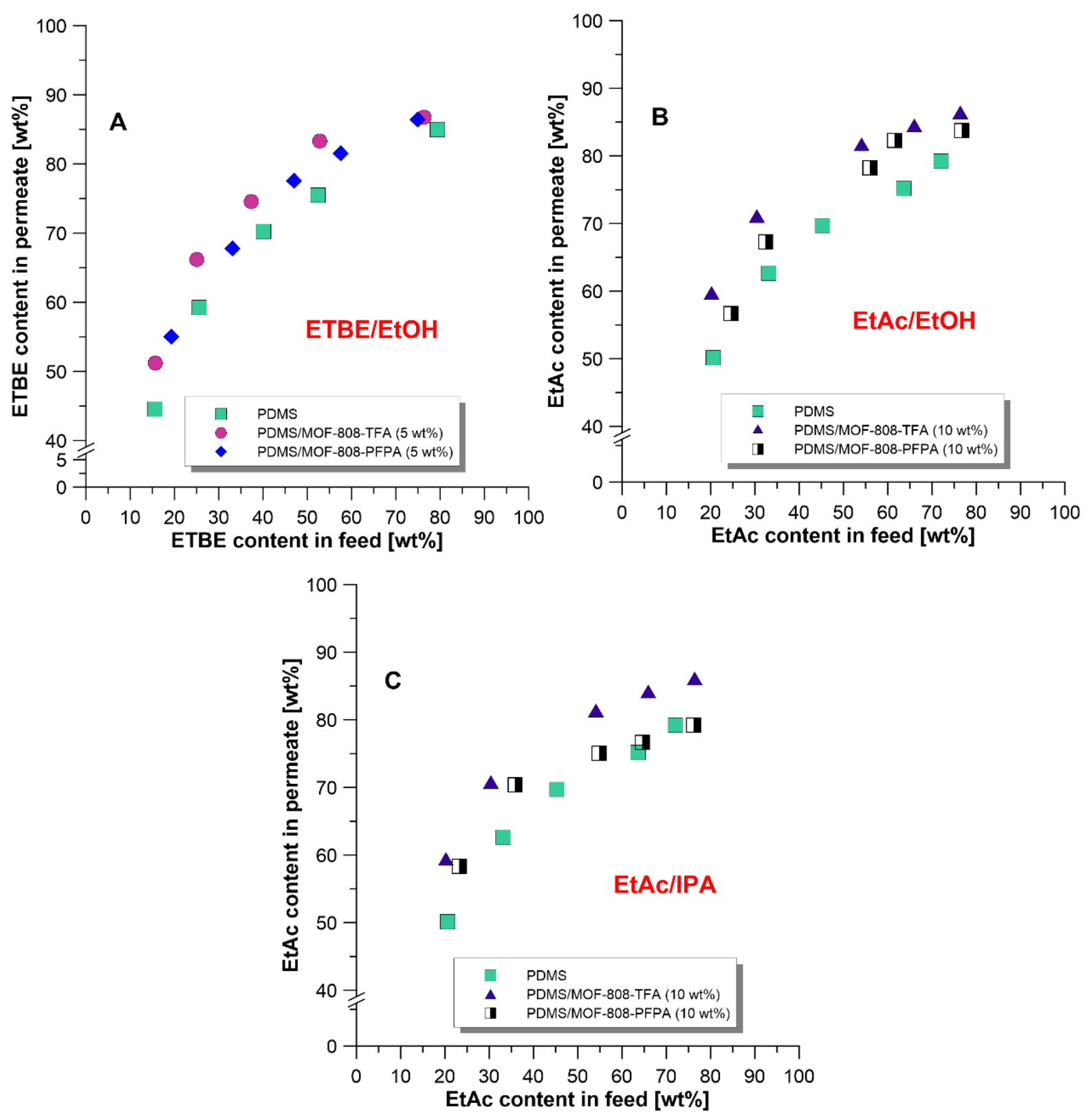

Figure 9. McCabe-Thiele separation diagrams for investigated membranes in contact with ETBE/EtOH (A), EtAc/EtOH (B), and EtAc/IPA (C) mixtures.

A comparison of separation factors $(\beta)$ and thickness normalized Pervaporation Separation Indexes $\left(P S I_{N}\right)$ are presented in Figure 10. It should be mentioned that the fluxes of preferentially transported components increased with increasing the content of this compound in feed solutions (ethyl acetate or ethyl tert-butyl ether). According to the calculated distance parameters (Table 8), the affinity between the membranes and the tested mixtures increases with increasing content of ethyl acetate or ethyl tert-butyl ether in the mixtures. 

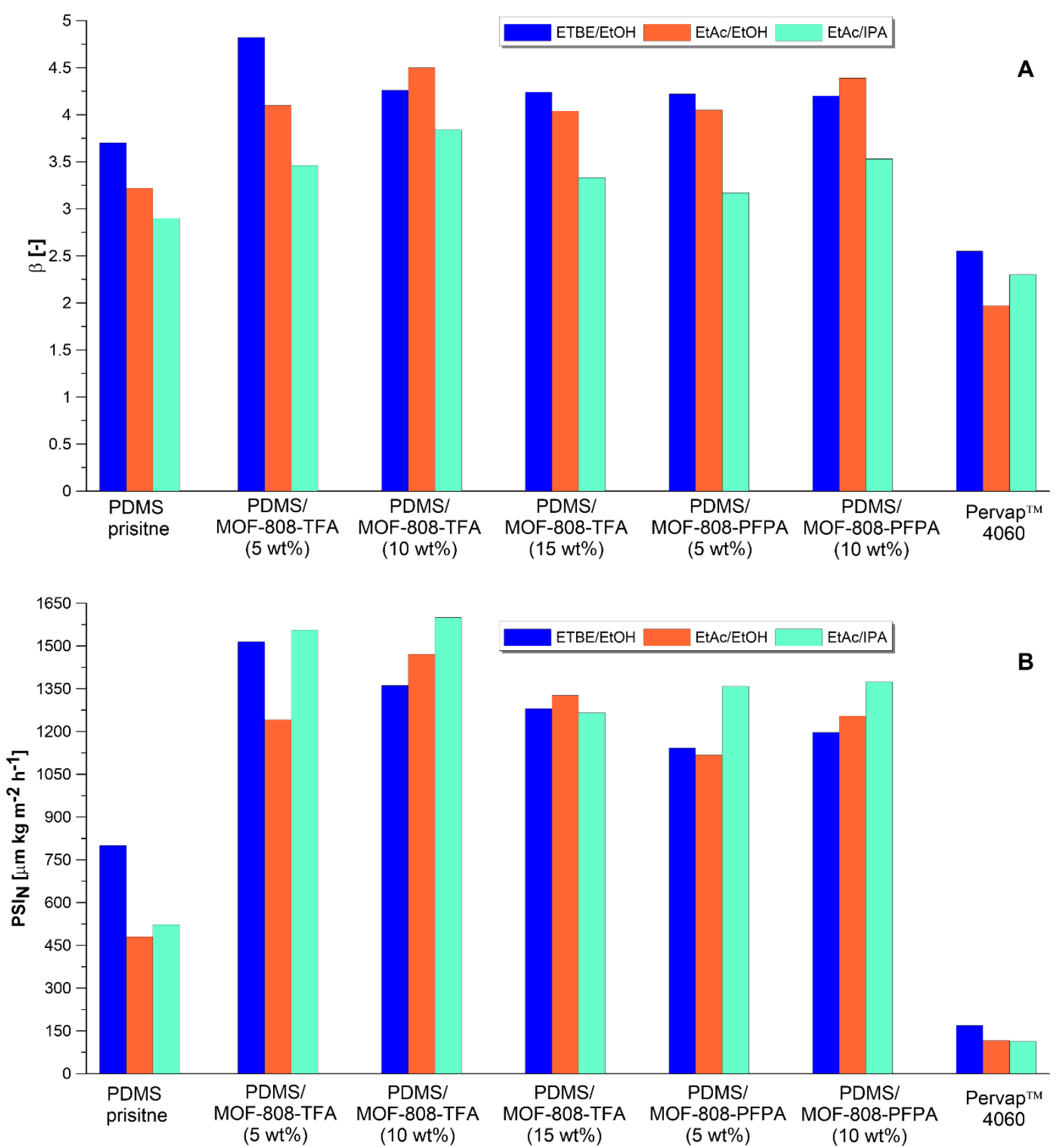

Figure 10. Comparison of separation factor (A) and thickness normalized Pervaporation Separation Index (B) obtained during the separation of mixtures containing $40 \mathrm{wt} \%$ of ETBE or EtAc.

Comparing the data obtained for pristine PDMS membrane, it was found that this membrane demonstrates the best efficiency in the separation of ETBE/EtOH, while the lowest separation factor was noticed for EtAc/IPA mixtures (Figure 10A). Pervaporation results show that the incorporation of MOF particles caused an increase in the separation factor. Taking into account separated mixtures, it can be concluded that the best efficiency in the separation of EtAc/EtOH and EtAc/IPA mixtures was found for PDMS/MOF-808-TFA (10 wt\%) membranes. In the case of $\mathrm{EtAc/EtOH}$, the separation factor is 1.2 times higher than for 
the pristine PDMS membrane, while the separation factor increases from 2.9 to 3.4 for the EtAc/IPA mixtures. The obtained results showed that PDMS/MOF-808-TFA (5 wt\%) demonstrated the best efficiency in the separation of ETBE/EtOH mixtures. The separation factor increases from 3.7 to 4.8. Moreover, an increase in MOF content in the polymer matrix does not influence the membrane separation ability in contact with the ETBE/EtOH mixture. It should be highlighted that due to the similar physiochemical nature of separated components, it is challenging to achieve a significant improvement in the separation properties of membranes. Taking into account the commercial Pervap ${ }^{\text {TM}} 4060$ membrane, it demonstrated the best efficiency during the separation of the ETBE/EtOH mixture, and the lowest one for $\mathrm{EtAc/EtOH}$.

It was noticed that in the case of PDMS/MOF-808-TFA (5 wt $\%)$ and PDMS/MOF-808-PFPA (5 wt\%) membranes, better performances in the separation of ETBE/EtOH and EtAc/IPA were found for PDMS/MOF-808-TFA (5 wt\%), while during the separation of EtAc/EtOH both membranes demonstrated similar separation ability (Figure 10A). Comparison of the efficiency of PDMS/MOF-808-TFA (10 wt $\%)$ and PDMS/MOF-808-PFPA (10 wt\%) membranes leads to the conclusion that both membranes possess similar efficiency in the separation of ETBE/EtOH mixtures. It was also noticed that, in the case of EtAc/EtOH and EtAc/IPA mixtures, PMDS/MOF-808-TFA (10 wt\%) performed better (Figure 10A).

Pervaporation results showed that the both pristine and filled PDMS membranes demonstrated a better efficiency in the separation of EtAc/EtOH mixtures compared with the efficiency obtained during the pervaporation of EtAc/IPA mixtures. Similarly, to the laboratory-made membranes, Pervap ${ }^{\text {TM}} 4060$ showed the best ability to separate the ETBE/EtOH mixture. In this case, obtained pervaporation results are in good accordance with the calculated distance parameter (higher separation factor for EtAc/IPA mixture). Comparing the laboratory-made membranes with commercial Pervap ${ }^{\text {TM} 4060 ~ m e m b r a n e, ~ i t ~ w a s ~}$ found that both pristine and filled PDMS membranes showed significantly better separation properties (Figure 10A).

Separation in pervaporation takes place due to the differences in the membrane affinity for the component of the mixture, whereas diffusion depends on the free volume in polymer matrix [37]. The incorporation of MOF particles rearrange the polymer chains and consequently changes the free volume and permeation flux [67]. Additionally, MOF particles are characterized by a porous structure. The pore sizes of MOF-808-TFA and MOF-808-PFPA are much larger than the molecular diameters of ethyl acetate (4.95 $\AA$ [68]), ethanol 
(4.5 ̊ [69]), isopropanol (4.3 ̊ [70]), and ethyl tert-butyl ether. That means that components can freely pass through the pores of the fillers and MOF particles serve as a highly permeable region. However, it should be mentioned that separated components possess various polarities. The relative polarity of ethyl acetate is equal to 0.228 , while ethanol and isopropanol have a relative polarity of 0.654 and 0.488 , respectively [71]. Comparing the separated mixtures, ethyl acetate is less polar than ethanol and isopropanol, and ethyl tert-butyl ether is less polar than ethanol. MOF-808-TFA and MOF-808-PFPA possess a hydrophobic character. Therefore, those highly permeable regions created by MOF particles are available to EtAc and ETBE molecules, while ethanol and isopropanol molecules have less affinity for the MOF. As a result, the separation ability of the filled membranes is higher. Comparing the modulators inside the MOF particles, membranes modified by MOF-808-PFPA showed a lower separation factor. This can be related to a higher degree of polymer rigidification after modification by PFPA.

Figure 10B presents the comparison of the thickness normalised Pervaporation Separation Indexes $\left(P S I_{N}\right)$. The $P S I$ is a parameter used to assess the effectiveness of various membranes in the separation of a certain mixture. According to Eq. (14), $P S I_{N}$ combines the separation factor and thickness normalised flux. The higher the value of the $P S I_{N}$, the more efficient the membrane is. In the case of pristine PDMS, the highest $P S I_{N}$ value was found for the ETBE/EtOH mixture and the lowest one for EtAc/EtOH. Taking into account the influence of incorporation of MOF particles, the filled membrane showed a significantly higher $P S I_{N}$ compared with the pristine PDMS membrane. The $P S I_{N}$ of the PDMS/MOF-808-TFA (10 wt\%) membrane is 3 times higher (EtAc/IPA) than that for the pristine PDMS membrane.

Moreover, a comparison of $P S I_{N}$ values for the separation of ETBE/EtOH, and EtAc/IPA with filled membranes containing the same amount of nanoparticles ( $5 \mathrm{wt} \%$ ) revealed a higher $P S I_{N}$ value in the separation of ETBE/EtOH and EtAc/IPA mixtures, while PDMS/MOF-808-PFPA (5 wt\%) showed a higher $P S I_{N}$ in the pervaporation with EtAc/EtOH. In the case of PDMS/MOF-808-TFA (10 wt\%) and PDMS/MOF-808-PFPA (10 wt $\%$ ) membranes, in all experiments, a higher value of $P S I_{N}$ was achieved with PDMS/MOF-808-TFA (10 wt\%).

Similarly to the comparison of separation factor $\beta$, lab-made membranes demonstrated

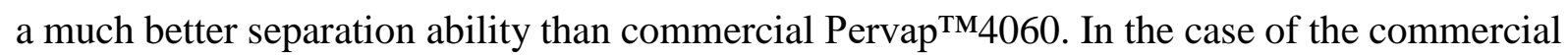
membrane, the highest $P S I_{N}$ was achieved during the separation of ETBE/EtOH. 


\subsection{Influence of water in the feed solution}

It should be remembered that all solvents contain traces of water. Understanding the influence of water on membrane behaviour is necessary for the further development of organic-organic pervaporation. In our previous work, we proposed the enrichment factor (Eq. (15)) of water as a tool for evaluating the effect of water presence on the behaviour of the membranes [72].

$E F_{\text {water }}=\frac{P_{w}}{F_{w}}$

where $P_{w}$ and $F_{w}$ are the content of water in permeate and feed, respectively.

Table 11. Comparison of enrichment factor of water of PDMS based membranes.

\begin{tabular}{lccc}
\hline \multirow{2}{*}{ Membranes } & \multicolumn{3}{c}{$\boldsymbol{E F}_{\text {water }}[-]$} \\
\cline { 2 - 4 } & EtAc/EtOH & EtAc/IPA & ETBE/EtOH \\
\hline PDMS & 1.27 & 1.78 & 0.89 \\
PDMS/MOF-808-TFA (5 wt \%) & 0.95 & 1.06 & 0.88 \\
PDMS/MOF-808-TFA (10 wt\%) & 0.91 & 1.00 & 0.91 \\
PDMS/MOF-808-TFA (15 wt\%) & 0.89 & 0.96 & 0.76 \\
& & & \\
PDMS/MOF-808-PFPA (5 wt \%) & 0.94 & 1.00 & 0.80 \\
PDMS/MOF-808-PFPA (10 wt\%) & 0.86 & 0.91 & 0.72 \\
\hline
\end{tabular}

A comparison of the calculated EFs of tested membranes is gathered in Table 11. A value of $E F_{\text {water }}$ lower than 1 means that water molecules are not preferentially transported through the membranes. The smallest enrichment factors of water were observed during the separation of ETBE/EtOH mixture, and the highest for EtAc/IPA (Table 11). This observation can be explained by a bigger difference in chemical properties between ethyl tert-butyl ether (ether) and ethanol than between ethyl acetate (ester) as well as ethanol/isopropanol (alcohol). Esters are more similar to alcohols. Comparing the mixtures containing ethyl acetate, a higher $E F_{\text {water }}$ value was noticed for the ethyl acetate/isopropanol mixtures. These results can be clarified by the higher value of uptake (Figure 8 ) in contact with isopropanol. As a result of swelling, the distance between polymer chains increases, which facilitates the transport of water through the membranes. It should be highlighted that water possesses a smaller kinetic diameter (2.65 $\AA$ [73]) than isopropanol (4.3 $\AA$ [70]).

Comparing the data for filled membrane (Table 11), it is clear that the incorporation of MOF particles decreases the EF. Moreover, only in the case of membranes modified with MOF-808-PFPA, an increase in the MOF loading caused a further reduction of $E F_{\text {water }}$. This effect was not observed for the membranes containing MOF-808-TFA. Comparing the 2 
modulators (TFA/PFPA), a lower EF was found for membranes customised by MOF-808-PFPA. MOF-808-PFPA is characterised by a more hydrophobic character.

\section{Conclusions}

New types of mixed matrix membranes based on PDMS and fluorinated MOF- 808 were generated. During the synthesis of MOF nanofillers, two types of hydrophobic modulators i.e. trifluoroacetic acid (TFA) and pentafluoropropionic acid (PFPA) were selected. The type of filler has an impact on the overall physicochemical and materials properties of the generated membranes. An increase of roughness as well as contact angle was observed for the MMMs, especially for the materials containing PFPA. A substantial reduction in the polar part of the surface free energy was noticed for the PFPA materials, which was related to their higher hydrophobicity. For the first time, MMM with fluorinated MOF-808 were implemented in the pervaporative separation of solvent mixtures of industrial importance, i.e. ethyl acetate-EtAc and ethyl tert-butyl ether-ETBE. The MOF loading has a noticeable influence on the transport and separation properties of the materials. The most effective membrane for the separation of ETBE/EtOH was PDMS/MOF808-TFA (5 wt\%) membrane $\left(P S I_{N}=1540 \mu \mathrm{m} \mathrm{kg} \mathrm{m}^{-2} \mathrm{~h}^{-1}\right)$, while a non-filled membrane was characterized by $P S I_{N}=780 \mu \mathrm{m} \mathrm{kg} \mathrm{m}^{-2} \mathrm{~h}^{-1}$. On the other hand, for the separation of EtAc based mixtures, membranes with higherMOF-loadings were more effective. The applied Hansen Solubility Parameter theory helped in understanding the link between separation performance and membrane material. Finally, the relation between the water content in the feed on the membrane performance has been also studied. Less water permeated by the addition of hydrophobic MOF fillers.

\section{Acknowledgements}

This work was supported by the Preludium 13 grant (2017/25/N/ST5/01097) from The National Science Center (NSC). The NSC PhD scholarship for Katarzyna Knozowska within the frame of the Etiuda 6 project (2018/28/T/ST5/00411) is kindly acknowledged.

Raymond Thür is grateful to the FWO for their financial support through a FWO-SB grant $(1 \mathrm{~S} 63317 \mathrm{~N})$.

The authors would like to thank the PKN Orlen S.A. for providing with the ethyl tertbutyl ether sample. 


\section{References}

[1] R. Baker, Membrane Technology and Applications, 2nd ed., John Wiley \& Sons, Ltd., Chichester, 2004.

[2] W. Li, F. Galiano, J. Estager, J.-C.M. Monbaliu, D.P. Debecker, A. Figoli, P. Luis, Sorption and pervaporation study of methanol/dimethyl carbonate mixture with poly(etheretherketone) (PEEK-WC) membrane, J. Membr. Sci., 567 (2018) 303-310.

[3] F. Galiano, A.H. Ghanim, K.T. Rashid, T. Marino, S. Simone, Q.F. Alsalhy, A. Figoli, Preparation and characterization of green polylactic acid (PLA) membranes for organic/organic separation by pervaporation, Clean Technol. Environ. Policy, 21 (2019) 109-120.

[4] P. Č́íhal, O. Vopička, M. Lanč, M. Kludský, J. Velas, Z. Hrdlička, A. Michalcová, M. Dendisová, K. Friess, Poly(butylene succinate)-cellulose triacetate blends: permeation, pervaporation, sorption and physical structure, Polym. Test., 65 (2018) 468-479.

[5] P. Luis, Chapter 3 - Pervaporation, in: P. Luis (Ed.) Fundamental Modelling of Membrane Systems, Elsevier, Amsterdam, 2018, pp. 71-102.

[6] V.V. Volkov, Separation of liquids by pervaporation through polymeric membranes, Russ. Chem. Bull., 43 (1994) 187-198.

[7] F. Galiano, F. Falbo, A. Figoli, Polymeric Pervaporation Membranes: Organic-Organic Separation, in: P.M. Visakh, O. Nazarenko (Eds.) Nanostructured Polymer Membranes, John Wiley \& Sons, Inc., Beverly, 2016, pp. 287-310.

[8] Y.K. Ong, G.M. Shi, N.L. Le, Y.P. Tang, J. Zuo, S.P. Nunes, T.-S. Chung, Recent membrane development for pervaporation processes, Prog. Polym. Sci., 57 (2016) 1-31.

[9] E. Nagy, Chapter 1 - Membrane Materials, Characterization, and Transport Properties, in: E. Nagy (Ed.) Basic Equations of Mass Transport Through a Membrane Layer (Second Edition), Elsevier, Amsterdam, 2019, pp. 1-10.

[10] X. Liu, Metal-organic framework UiO-66 membranes, Front. Chem. Sci. Eng., (2019).

[11] T. Rasheed, K. Rizwan, M. Bilal, H.M.N. Iqbal, Metal-Organic Framework-Based Engineered Materials-Fundamentals and Applications, Molecules, 25 (2020).

[12] Z. Jia, G. Wu, Metal-organic frameworks based mixed matrix membranes for pervaporation, Microporous Mesoporous Mater., 235 (2016) 151-159.

[13] J.H. Cavka, S. Jakobsen, U. Olsbye, N. Guillou, C. Lamberti, S. Bordiga, K.P. Lillerud, A New Zirconium Inorganic Building Brick Forming Metal Organic Frameworks with Exceptional Stability, J. Am. Chem. Soc., 130 (2008) 13850-13851. 
[14] K. Huang, B. Wang, S. Guo, K. Li, Micropatterned Ultrathin MOF Membranes with Enhanced Molecular Sieving Property, Angew. Chem., Int. Ed., 57 (2018) 13892-13896.

[15] S. Castarlenas, C. Téllez, J. Coronas, Gas separation with mixed matrix membranes obtained from MOF UiO-66-graphite oxide hybrids, J. Membr. Sci., 526 (2017) 205-211.

[16] J. Shen, G. Liu, K. Huang, Q. Li, K. Guan, Y. Li, W. Jin, UiO-66-polyether block amide mixed matrix membranes for $\mathrm{CO}_{2}$ separation, J. Membr. Sci., 513 (2016) 155-165.

[17] F. Wu, Y. Cao, H. Liu, X. Zhang, High-performance UiO-66-NH2 tubular membranes by zirconia-induced synthesis for desulfurization of model gasoline via pervaporation, J. Membr. Sci., 556 (2018) 54-65.

[18] M.W. Anjum, F. Vermoortele, A.L. Khan, B. Bueken, D.E. De Vos, I.F.J. Vankelecom, Modulated UiO-66-Based Mixed-Matrix Membranes for $\mathrm{CO}_{2}$ Separation, ACS Appl. Mater. Interfaces, 7 (2015) 25193-25201.

[19] R. Custelcean, V. Sellin, B.A. Moyer, Sulfate separation by selective crystallization of a urea-functionalized metal-organic framework, Chem. Commun., (2007) 1541-1543.

[20] K.K. Tanabe, S.M. Cohen, Postsynthetic modification of metal-organic frameworks-a progress report, Chem. Soc. Rev., 40 (2011) 498-519.

[21] H.H. Mautschke, F. Drache, I. Senkovska, S. Kaskel, F.X. Llabrés i Xamena, Catalytic properties of pristine and defect-engineered Zr-MOF-808 metal organic frameworks, Catal. Sci. Technol., 8 (2018) 3610-3616.

[22] R. Thür, N. Van Velthoven, V. Lemmens, M. Bastin, S. Smolders, D. De Vos, I.F.J. Vankelecom, Modulator-Mediated Functionalization of MOF-808 as a Platform Tool to Create High-Performance Mixed-Matrix Membranes, ACS Appl. Mater. Interfaces, 11 (2019) 4479244801.

[23] K.F. Yee, A.R. Mohamed, S.H. Tan, A review on the evolution of ethyl tert-butyl ether (ETBE) and its future prospects, Renewable Sustainable Energy Rev., 22 (2013) 604-620.

[24] H.C.G. Nicholls, H.E.H. Mallinson, S.A. Rolfe, M. Hjort, M.J. Spence, S.F. Thornton, Influence of contaminant exposure on the development of aerobic ETBE biodegradation potential in microbial communities from a gasoline-impacted aquifer, J. Hazard. Mater., 388 (2020) 122022.

[25] E.W. de Menezes, R. Cataluña, D. Samios, R.d. Silva, Addition of an azeotropic ETBE/ethanol mixture in eurosuper-type gasolines, Fuel, 85 (2006) 2567-2577.

[26] E.W. de Menezes, R. Cataluña, Optimization of the ETBE (ethyl tert-butyl ether) production process, Fuel Process. Technol., 89 (2008) 1148-1152. 
[27] X. Yao, Y. Liu, T. Li, T. Zhang, H. Li, W. Wang, X. Shen, F. Qian, Z. Yao, Adsorption behavior of multicomponent volatile organic compounds on a citric acid residue waste-based activated carbon: Experiment and molecular simulation, J. Hazard. Mater., 392 (2020) 122323. [28] Q. Pan, X. Shang, S. Ma, J. Li, Y. Song, M. Sun, J. Liu, L. Sun, Control comparison of extractive distillation configurations for separating ethyl acetate-ethanol-water ternary mixture using ionic liquids as entrainer, Sep. Purif. Technol., 236 (2020) 116290.

[29] T. Shi, W. Chun, A. Yang, Y. Su, S. Jin, J. Ren, W. Shen, Optimization and control of energy saving side-stream extractive distillation with heat integration for separating ethyl acetate-ethanol azeotrope, Chem. Eng. Sci., 215 (2020) 115373.

[30] A. Hasanoğlu, Y. Salt, S. Keleşer, S. Özkan, S. Dinçer, Pervaporation separation of organics from multicomponent aqueous mixtures, Chem. Eng. Process., 46 (2007) 300-306.

[31] K. Knozowska, G. Li, W. Kujawski, J. Kujawa, Novel heterogeneous membranes for enhanced separation in organic-organic pervaporation, J. Membr. Sci., 599 (2020) 117814.

[32] M. Wang, C. Arnal-Herault, C. Rousseau, A. Palenzuela, J. Babin, L. David, A. Jonquieres, Grafting of multi-block copolymers: A new strategy for improving membrane separation performance for ethyl tert-butyl (ETBE) bio-fuel purification by pervaporation, J. Membr. Sci., 469 (2014) 31-42.

[33] A. Jonquières, R. Clément, P. Lochon, New film-forming poly(urethane-amide-imide) block copolymers: influence of soft block on membrane properties for the purification of a fuel octane enhancer by pervaporation, Eur. Polym. J., 41 (2005) 783-795.

[34] F. Hassan Hassan Abdellatif, J. Babin, C. Arnal-Herault, C. Nouvel, J.-L. Six, A. Jonquieres, Bio-based membranes for ethyl tert-butyl ether (ETBE) bio-fuel purification by pervaporation, J. Membr. Sci., 524 (2017) 449-459.

[35] S. Zereshki, A. Figoli, S.S. Madaeni, F. Galiano, E. Drioli, Pervaporation separation of ethanol/ETBE mixture using poly(lactic acid)/poly(vinyl pyrrolidone) blend membranes, J. Membr. Sci., 373 (2011) 29-35.

[36] J. Kujawa, A. Rozicka, S. Cerneaux, W. Kujawski, The influence of surface modification on the physicochemical properties of ceramic membranes, Colloids Surf., A, 443 (2014) 567575.

[37] J.G. Wijmans, R.W. Baker, The solution-diffusion model - a review, J. Membr. Sci., 107 (1995) 1-21.

[38] M.O. Mavukkandy, M.R. Bilad, J. Kujawa, S. Al-Gharabli, H.A. Arafat, On the effect of fumed silica particles on the structure, properties and application of PVDF membranes, Sep. Purif. Technol., 187 (2017) 365-373. 
[39] L. Paseta, G. Potier, S. Abbott, J. Coronas, Using Hansen solubility parameters to study the encapsulation of caffeine in MOFs, Org. Biomol. Chem., 13 (2015) 1724-1731.

[40] D. Elangovan, U. Nidoni, I.E. Yuzay, S.E.M. Selke, R. Auras, Poly(l-lactic acid) Metal Organic Framework Composites. Mass Transport Properties, Ind. Eng. Chem. Res., 50 (2011) 11136-11142.

[41] A. Kujawska, K. Knozowska, J. Kujawa, W. Kujawski, Influence of downstream pressure on pervaporation properties of PDMS and POMS based membranes, Sep. Purif. Technol., 159 (2016) 68-80.

[42] C.M. Hansen, Hansen Solubility Parameters. A User's Book, second ed., CRC Press, London, New York, 2007.

[43] R.F. Fedors, A method for estimating both the solubility parameters and molar volumes of liquids, Polym. Eng. Sci., 14 (1974) 147-154.

[44] A. Kujawska, K. Knozowska, J. Kujawa, G. Li, W. Kujawski, Fabrication of PDMS based membranes with improved separation efficiency in hydrophobic pervaporation, Sep. Purif. Technol., 234 (2020) 116092.

[45] R.W. Baker, J.G. Wijmans, Y. Huang, Permeability, permeance and selectivity: A preferred way of reporting pervaporation performance data, J. Membr. Sci., 348 (2010) 346352.

[46] E. Rynkowska, K. Dzieszkowski, A. Lancien, K. Fatyeyeva, A. Szymczyk, J. Kujawa, S. Koter, S. Marais, A. Wolan, W. Kujawski, Physicochemical properties and pervaporation performance of dense membranes based on cellulose acetate propionate (CAP) and containing polymerizable ionic liquid (PIL), J. Membr. Sci., 544 (2017) 243-251.

[47] C. Ardila-Suárez, J. Rodríguez-Pereira, V.G. Baldovino-Medrano, G.E. RamírezCaballero, An analysis of the effect of zirconium precursors of MOF-808 on its thermal stability, and structural and surface properties, Crystengcomm, 21 (2019) 1407-1415.

[48] S.E. López, J. Salazar, Trifluoroacetic acid: Uses and recent applications in organic synthesis, J. Fluorine Chem., 156 (2013) 73-100.

[49] N.C.f.B. Information, PubChem Database. Pentafluoropropionic acid, https://pubchem.ncbi.nlm.nih.gov/compound/Pentafluoropropionic-acid, Mar. 28, 2020

[50] K. Xuan, Y. Pu, F. Li, J. Luo, N. Zhao, F. Xiao, Metal-organic frameworks MOF-808-X as highly efficient catalysts for direct synthesis of dimethyl carbonate from $\mathrm{CO}_{2}$ and methanol, Chin. J. Catal., 40 (2019) 553-566.

[51] J. Xu, J. Liu, Z. Li, X. Wang, Z. Wang, Synthesis, structure and properties of Pd@MOF808, J. Mater. Sci., 54 (2019) 12911-12924. 
[52] K.S.W. Sing, D.H. Everett, R.A.W. Haul, L. Moscou, R.A. Pierotti, J. Rouquérol, T. Siemieniewska, Reporting Physisorption Data for Gas/Solid Systems With Special Reference to the Determination of Surface Area and Porosity, in: IUPAC Standards Online, International Union of Pure and Applied Chemistry, Zürich, 1985, pp. 603-619.

[53] K. Healey, W. Liang, P.D. Southon, T.L. Church, D.M. D'Alessandro, Photoresponsive spiropyran-functionalised MOF-808: postsynthetic incorporation and light dependent gas adsorption properties, J. Mater. Chem. A, 4 (2016) 10816-10819.

[54] Z.-J. Lin, H.-Q. Zheng, J. Chen, W.-E. Zhuang, Y.-X. Lin, J.-W. Su, Y.-B. Huang, R. Cao, Encapsulation of Phosphotungstic Acid into Metal-Organic Frameworks with Tunable Window Sizes: Screening of PTA@MOF Catalysts for Efficient Oxidative Desulfurization, Inorg. Chem., 57 (2018).

[55] C. Jia, F.G. Cirujano, B. Bueken, B. Claes, D. Jonckheere, K.M. Van Geem, D. De Vos, Geminal Coordinatively Unsaturated Sites on MOF-808 for the Selective Uptake of Phenolics from a Real Bio-Oil Mixture, ChemSusChem, 12 (2019) 1256-1266.

[56] Q. Liu, Q. Zhang, B. Liu, J. Ma, A new synthesis and adsorption mechanism of $\mathrm{ZrO}_{2}$ based metal-organic frames for efficient removal of mercury ions from aqueous solution, Ceram. Int., 45 (2019) 15720-15724.

[57] Z. Su, Y.-R. Miao, G. Zhang, J. Miller, K. Suslick, Bond breakage under pressure in a metal organic framework, Chem. Sci., 8 (2017).

[58] V.I. Isaeva, L.M. Kustov, Chapter 2 - Metal-Organic Frameworks and Related Materials: Miles to Go, in: B.F. Sels, L.M. Kustov (Eds.) Zeolites and Zeolite-Like Materials, Elsevier, Amsterdam, 2016, pp. 33-109.

[59] J. Xu, J. Liu, Z. Li, X. Wang, Y. Xu, S. Chen, Z. Wang, Optimized synthesis of Zr(iv) metal organic frameworks (MOFs-808) for efficient hydrogen storage, New J. Chem., 43 (2019) 4092-4099.

[60] C. Ardila-Suárez, D.R. Molina V, H. Alem, V.G. Baldovino-Medrano, G.E. RamírezCaballero, Synthesis of ordered microporous/macroporous MOF-808 through modulatorinduced defect-formation, and surfactant self-assembly strategies, Phys. Chem. Chem. Phys., 22 (2020) 12591-12604.

[61] X. Liu, L. Zhang, J. Wang, Design Strategies for MOF-derived Porous Functional Materials: Preserving Surfaces and Nurturing Pores, J. Materiomics, (2020).

[62] Michael J. Owen, P.R. Dvornic, Silicone Surface Science, first ed., Springer, Dordrecht, 2012. 
[63] G. Camino, S.M. Lomakin, M. Lazzari, Polydimethylsiloxane thermal degradation Part 1. Kinetic aspects, Polymers, 42 (2001) 2395-2402.

[64] Z. Si, D. Cai, S. Li, G. Li, Z. Wang, P. Qin, A high-efficiency diffusion process in carbonized ZIF-8 incorporated mixed matrix membrane for n-butanol recovery, Sep. Purif. Technol., 221 (2019) 286-293.

[65] Y.M. Xu, T.-S. Chung, High-performance UiO-66/polyimide mixed matrix membranes for ethanol, isopropanol and n-butanol dehydration via pervaporation, J. Membr. Sci., 531 (2017) 16-26.

[66] A. Rozicka, J. Niemisto, R.L. Keiski, W. Kujawski, Apparent and intrinsic properties of commercial PDMS based membranes in pervaporative removal of acetone, butanol and ethanol from binary aqueous mixtures, J. Membr. Sci., 453 (2014) 108-118.

[67] G. Choudalakis, A.D. Gotsis, Free volume and mass transport in polymer nanocomposites, Curr. Opin. Colloid Interface Sci., 17 (2012) 132-140.

[68] S.D. Manjare, A.K. Ghoshal, Comparison of Adsorption of Ethyl Acetate on Activated Carbon and Molecular Sieves 5A and 13X, J. Chem. Eng. Data, 51 (2006) 1185-1189.

[69] R. Sankar Ganesh, M. Navaneethan, G.K. Mani, S. Ponnusamy, K. Tsuchiya, C. Muthamizhchelvan, S. Kawasaki, Y. Hayakawa, Influence of Al doping on the structural, morphological, optical, and gas sensing properties of $\mathrm{ZnO}$ nanorods, J. Alloys Compd., 698 (2017) 555-564.

[70] H. Sudhakar, Y. Maruthi, U.S.K. Rao, C.V. Prasad, M. Subha, S. Sridhar, K.C. Rao, Improved pervaporation performance of $13 \mathrm{X}$ zeolite filled chitosan membranes, Indian J. Adv. Chem. Sci., 2 (2013) 21-31.

[71] Christian Reichardt, T. Welton, Solvents and Solvent Effects in Organic Chemistry, 3rd ed., WILEY-VCH Verlag GmbH \& Co., Weinheim, 2008.

[72] R. Kopeć, M. Meller, W. Kujawski, J. Kujawa, Polyamide-6 based pervaporation membranes for organic-organic separation, Sep. Purif. Technol., 110 (2013) 63-73.

[73] C. Scholes, S. Kentish, G. Stevens, Carbon Dioxide Separation through Polymeric Membrane Systems for Flue Gas Applications, Recent Pat. Chem. Eng., 1 (2008) 52-66. 